\title{
Oxygen isotopes in calcite grown under
}

\section{cave-analogue conditions}

\author{
Authors C. C. Day and G.M. Henderson \\ Address Department of Earth Sciences, Oxford University, South Parks Road, Oxford, OX1 3AN, UK \\ Email_chris.day@earth.ox.ac.uk \\ Journal GCA \\ Version Version 3 of manuscript, submitted on 12 March 2011 \\ Keywords palaeoclimate, stalagmite, cave geochemistry, speleothem, oxygen isotopes
}




\section{- Abstract}

2 Speleothem oxygen isotopes and growth rates are valuable proxies for reconstructing climate history. There

3 is debate, however, about the conditions that allow speleothems to grow in oxygen isotope equilibrium, and

4 about the correct equilibrium fractionation factors. We report results from a series of carbonate growth ex-

5 periments in karst-analogue conditions in the laboratory. The setup closely mimics natural processes (e.g.

6 precipitation driven by $\mathrm{CO}_{2}$-degassing, low ionic strength solution, thin solution film) but with a tight control

7 on growth conditions (temperature, $\mathrm{pCO}_{2}$, drip rate, calcite saturation index and the composition of the ini-

$s$ tial solution). Calcite is dissolved in water in a 20,000 ppmV $\mathrm{pCO}_{2}$ environment. This solution is dripped

9 onto glass plates (coated with seed-carbonate) in a lower $\mathrm{pCO}_{2}$ environment ( $<2500 \mathrm{ppmV}$ ), where degassing leads to calcite growth. Experiments were performed at 7, 15, 25 and $35^{\circ} \mathrm{C}$. At each temperature, calcite was grown at three drip rates (2, 6 and 10 drips per minute) on separate plates. The mass of calcite grown in these experiments varies with temperature ( $\mathrm{T}$ in $\mathrm{K}$ ) and drip rate (d_r in drips $\mathrm{min}^{-1}$ ) according to the relationship dailygrowthmass $=1.254+1.478 * 10^{-9} * e^{0.0679 T}+\left(e^{0.00248 T}-2\right) *\left(-0.779 d \_r^{2}+10.05 d \_r+11.69\right)$. This relationship indicates a substantial increase of growth mass with temperature, a smaller influence of drip rate on growth mass at low temperature and a non-linear relationship between drip rate and growth mass at higher temperatures. Low temperature, fast dripping conditions are found to be the most favourable for reducing effects associated with evaporation and rapid depletion of the dissolved inorganic carbon reservoir (rapid DIC-depletion). The impact of evaporation can be large so caves with high relative humidity are also preferable for paleaoclimate reconstruction. Even allowing for the maximum offsets that may have been induced by evaporation and rapid DIC-depletion, $\delta^{18} O$ measured in some of our experiments remain higher than those predicted by Kim \& O’Neil (1997). Our new results are well explained by equilibrium at a significantly higher $\alpha_{\text {calcite-water }}$, with a kinetic-isotope effect that favours ${ }^{16} \mathrm{O}$ incorporation as growth rate increases. This scenario agrees with recent studies by Coplen (2007) and Dietzel et al. (2009). Overall, our results suggest that three separate processes cause $\delta^{18} O$ to deviate from true isotope equilibrium in the cave environment. Two of these drive $\delta^{18} O$ to higher values (evaporation and rapid DIC-depletion) while one drives $\delta^{18} O$ to lower values (preferential incorporation of ${ }^{16} \mathrm{O}$ in the solid carbonate at faster growth rates). While evaporation and DIC-depletion can be avoided in some settings, the third may be inescapable in the cave environment and means that any temperature to $\delta^{18} O$ relationship is an approximation. The controlled conditions of the present experiments also display limitations in the use of the Hendy test to identifying equilibrium growth. 


\section{зо 1 Introduction}

Speleothems are increasingly recognized as valuable recorders of past climate and as a tool for understanding climate processes (e.g. Wang et al. 2004, Dykoski et al. 2005, Henderson 2006). Their suitability as palaeoclimate archives stems from the unique environment of cave systems which allow high-resolution deposition and preservation of calcite in widespread geographic locations. Oxygen isotopes have proved the most widely applied palaeoclimate proxy with which to reconstruct the past (Bar-Matthews et al. 2003, Wang et al. 2001, Fleitmann et al. 2003) but the controls on $\delta^{18} O$ in stalagmites are complex. The $\delta^{18} O$ of infiltrated meteoric solution as a primary source of cave solution is controlled by variables including atmospheric temperature, altitude, sources of water, and the amount of rainfall (e.g. Dansgaard 1964, Ayalon et al. 1998, Zhang et al. 2004, McDermott 2004, Treble et al. 2005, LeGrande \& Schmidt 2006, Lachniet 2009). Once in the cave, further control is exerted on $\delta^{18} O_{\text {speleothem }}$ by evaporation, cave temperature, and the presence/absence of chemical equilibrium during carbonate formation. This study seeks to understand these in-cave controls on $\delta^{18} O$ so that stalagmite samples can be assessed for their suitability as recorders of past cave solution.

Hendy (1971) provided early insight into the theoretical aspects governing oxygen and carbon isotopes in speleothem samples and into the main controls affecting $\delta^{18} O_{\text {calcite }}$ equilibrium / disequilibrium occurring at the speleothem surface. He identified three modes of speleothem formation: i) equilibrium loss of $\mathrm{CO}_{2}$, ii) kinetic loss of $\mathrm{CO}_{2}$ and iii) evaporation of water, of which only the first mode of formation results in $\delta^{18} \mathrm{O}_{\text {calcite }}$ being considered to be in equilibrium with rainwater $\delta^{18} O_{H_{2} O}$. Theoretical considerations from Hendy (1971) also led to the so called 'Hendy Test', which concludes that simultaneous enrichment of $\delta^{18} O$ and $\delta^{13} C$ along a growth layer of a stalagmite is indicative of kinetic fractionation, a test which is used to establish whether equilibrium growth applies to past stalagmite growth. The Hendy test has however recently been questioned as a reliable tool to identify $\delta^{18} O$ disequilibrium in stalagmites. Mickler et al. (2006) for instance questioned the result of many Hendy tests cited in the literature, based on along-growth-axis positive correlations between $\delta^{13} C$ and $\delta^{18} O$. This along-axis approach has, in any case, been disputed due to environmental conditions that can simultaneously affect both $\delta^{13} C$ and $\delta^{18} O$ of speleothem calcite (e.g. Dorale et al. 1998, Genty et al. 2003). Dorale \& Liu (2009), however, point out that even the true Hendy test (i.e. conducted along a single growth layer) has limitations because it cannot establish whether equilibrium is present at the growth axis.

For present-day stalagmite growth, verification of equilibrium conditions can be made by comparing measured $\delta^{18} O$ in the carbonate and the drip-waters, and by using a published equation describing the equilibrium relationship of $\alpha_{\text {calcite-water }}$ with temperature. Most assessments of this equilibrium relationship, including the 
most commonly used Kim \& O’Neil (1997) equation, have been based on laboratory growth of carbonate under carefully controlled laboratory conditions.

Recent work has, however, questioned the validity of the widely used Kim \& O’Neil (1997) equation for use in at least some natural settings. Zeebe (1999) proposed an additional pH control on $\delta^{18} O$ fractionation to explain variations in foraminifera grown at the same temperature but varying carbonate ion concentration (Spero et al. 1997). Subsequent studies have also suggested a growth rate control. Measurements by Coplen (2007) in very slowly forming calcite in a natural water-filled fissure at $33.7^{\circ} \mathrm{C}$ defined a significantly higher $\alpha_{\text {calcite-water }}$ than that of Kim \& O'Neil (1997). Laboratory experiments at varied growth rates (Dietzel et al. 2009) support the presence of a growth-rate control and also explain the lower $\alpha_{\text {calcite-water }}$ observed in previous laboratory studies.

These possible $\mathrm{pH}$ and growth rate controls on $\delta^{18} O$ fractionation have important implications for any branch of geochemistry that uses $\delta^{18} O$ to reconstruct past temperatures. In the stalagmite setting, for instance, the use of an inappropriate equation to link $\delta^{18} O$ fractionation and temperature could lead to incorrect conclusions about the (dis)equilibrium nature of growth, and/or to reconstruction of incorrect $\delta^{18} O$ for past rainwater.

For use of $\delta^{18} O$ as a reliable palaeoproxy in stalagmites, it is important to know: i) the range of conditions under which stalagmites form in isotopic equilibrium; ii) how to identify the presence/absence of disequilibrium

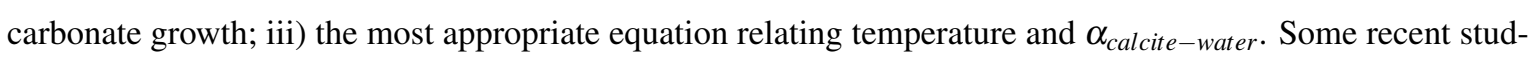
ies provide insight into these issues through study of conditions in active caves (e.g. Mickler et al. 2006, Genty 2008). These studies monitored cave conditions and grew calcite on glass plates under dripping stalactites. This provides valuable data for understanding the relationship between temperature, $\delta^{18} \mathrm{O}_{\mathrm{H}_{2} \mathrm{O}}$ and $\delta^{18} \mathrm{O}_{\text {calcite }}$ in a specific cave setting but does not allow for a rigorous understanding of stalagmite chemical mechanisms because of the multiple co-varying parameters in the cave setting (e.g. saturation index, temperature, drip rate, $\mathrm{CO}_{2}$-degassing rate). Calcite growth experiments in a controlled laboratory environment, on the other hand, enable environmental factors to be varied and assessed independently. There have been only three such calcite growth studies in cave-analogue growth conditions (Fantidis \& Ehhalt 1970, Huang \& Fairchild 2001, Wiedner et al. 2008), all of which differ from the natural cave setting in the way in which carbonate is grown. In particular, supersaturation and carbonate growth was induced by combining $\mathrm{CaCl}_{2}$ with $\mathrm{NaHCO}_{3}$. This differs from the natural process of $\mathrm{CO}_{2}$-degassing and results in elevated $\mathrm{Cl}^{-}$and $\mathrm{Na}^{+}$concentrations in solution. No existing study has driven calcite supersaturation directly by degassing of $\mathrm{CO}_{2}$ as occurs in the cave setting. Of the two previous experiments that reported $\delta^{18} O$ measurements (Fantidis \& Ehhalt 1970 and Wiedner et al. 2008), both used a setup of solution flow along a channel rather than dripping onto a surface. While impor- 
tant results came from these studies, neither reproduce the effects of drip development, drip impact and splash

effects that apply to stalagmite growth and which are expected to influence stalagmite stable isotope results.

In this study we describe an experimental procedure that is more representative of the growth conditions of stalagmites and allows for further assessment of the $\delta^{18} O$ response of stalagmite chemistry to cave growth conditions.

\section{Setup for stalagmite growth}

The goal of these experiments is to grow calcite in a controlled environment which is representative of the natural conditions of stalagmite growth. The laboratory setup developed to achieve these aims is illustrated in figure 1 and the experimental conditions are summarized in table 1.

The basic principle of the setup is simple, with two environments for the drip solution, one with high $\mathrm{pCO}_{2}$ in which calcite is dissolved to achieve a set saturation index and one with low $\mathrm{pCO}_{2}$ in which the aqueous $\mathrm{CO}_{2}$ degases and $\mathrm{CaCO}_{3}$ precipitates.

All materials used in these experiments were cleaned using standard procedure (Laxen \& Harrison 1981; Hall et al. 2002), i.e. a $48 \mathrm{~h}$ soak in 5-10\% $\mathrm{HNO}_{3}$, water-rinsed five times with deionized water and dried. Distilled $\mathrm{HNO}_{3}$ and $18 \mathrm{M} \Omega$, reverse-osmosis deionized water ('MilliQ') were used in all cases.

\section{Drip solution characteristics and dissolution environment}

The drip solution is a mixture of $18 M \Omega$ deionized water, dissolved VWR AnalR calcite and a solution containing a pre-determined mix of trace-metals. The addition of trace elements ensure that any minor chemical effects relating to presence of such element in the cave environments are mimicked accuretly, and also allow characterization of the controls on trace metal uptake into stalagmites. These results will be presented in a future manuscript

Drip solution characteristics were representative of the natural environment and were kept constant for the series of experiments at different temperatures and drip rates described here. Because $\mathrm{CO}_{2}$ solubility decreases with increasing temperature, it is not possible to maintain both saturation of $\mathrm{CaCO}_{3}\left(\mathrm{SI}_{\mathrm{CaCO}_{3}}\right)$ and calcium concentration $\left(\left[\mathrm{Ca}^{2+}\right]\right)$ constant over the range of temperatures $\left(7\right.$ to $35^{\circ} \mathrm{C}$ ). We varied $\left[\mathrm{Ca}^{2+}\right]$ to maintain a constant $\mathrm{SI}_{\mathrm{CaCO}_{3}}$ of 0.34 representative of the natural environment (e.g. Grotte de Villars, Baker et al. 1998). 
The saturation index of 0.34 is defined here as $\log 10\left(\frac{I A P}{K}\right)$, where IAP is the ion activity product of $C a^{2+}$ and $\mathrm{CO}_{3}^{2-}$ and $\mathrm{K}$ is the solubility product of calcite. The equivalent saturation ratio $\left(\Omega=\frac{I A P}{K}\right)$ is 2.2 . The saturation index is maintained constant by decreasing $\mathrm{Ca}$ with increasing experiment temperature. Saturations were calculated using PHREEQC (Parkhurst \& Appelo 1999).

The three components (deionized water, calcite and trace-metals mix) are added to a 25L Nalgene LDPE carboy, where they are thoroughly mixed and the calcite dissolved. The calcite (calculated and weighed for each temperature) is dissolved by bubbling pure $\mathrm{CO}_{2}$ through the solution under a $100 \% \mathrm{CO}_{2}$ atmosphere, with continual overhead stirring, both of which maximize dissolution efficiency. Dissolution proceeds at room temperature (20C) until complete $\mathrm{CaCO}_{3}$ dissolution is achieved (24-48h), as verified by visual inspection and $\mathrm{pH}$ monitoring. After complete dissolution, the $\mathrm{pCO}_{2}$ within the carboy is decreased to 20,000ppm and maintained at this level throughout the subsequent growth experiment by addition of laboratory air/ $\mathrm{CO}_{2}$ to decrease/increase the $\mathrm{pCO}_{2}$ as required. This 20,000ppmV value is typical for drip waters in a closed cave environment (e.g. Baker et al. 2000) and within the range of typical soil $\mathrm{pCO}_{2}$ values, 1,000 to 35,000ppm (McDermott 2004).

The $\mathrm{pCO}_{2}$ of the dissolution environment was monitored continuously with a Telaire $\mathrm{CO}_{2}$ monitor (Telaire 7001). The Telaire instrument operates in a small, separate culture flask that is connected as part of a closed system, to the dissolution carboy. The air/CO mix is pumped continuously through this two component system to ensure constant mixing of the headspace gas with the solution, and to ensure that a representative gas mix for $\mathrm{pCO}_{2}$ determination is available in the $\mathrm{CO}_{2}$ measurement flask.

\section{Flow rate, drip rate and drip volume}

Flow/drip rate is controlled using a multi-channel peristaltic pump (Gilson Minipuls 3). Two types of tubing are used: i) Tygon PVC tubing with internal diameters $0.25,0.76$ and $1.02 \mathrm{~mm}$ are fitted to the peristaltic pump and provide the three required drip rates for a single pump speed. A fourth Tygon PVC tube, internal diameter $1.52 \mathrm{~mm}$, removes the dripped-solution from the precipitation environment. ii) Narrow gauge PTFE tubing is used elsewhere (between the dissolution carboy \& pump and between the pump \& precipitation environment), minimizing residence time within the tubes and therefore minimizing potential in-tube calcite precipitation (which was monitored by subsequent nitric acid rinse and $\left[\mathrm{Ca}^{2+}\right]$ measurement and found to be trivial).

Upturned pipette tips $(1 \mathrm{~mL})$, connected to the PTFE tubing and held in place at the top of the precipitation container, proved effective for increasing tubing diameter over a short distance, thereby increasing the drip 
volume to $0.11 \mathrm{~mL}$. This worked by connecting the PTFE tubing to the narrow end of the pipette tip and letting the solution flow down the inner surface until forming a drip equal to the diameter of the opposite, wider end. It was the smooth and steadily increasing inner diameter that allowed this to happen without the solution simply flowing down one side of the inner pipette tip. We used this technique to maximize drip volume, thereby maximizing flow for a given drip rate and allowing for maximum degassing whilst the drip is forming (drip formation times are 38,10 and 6 seconds for the slow, medium and fast drip rates respectively). The drip volume achieved, $0.11 \mathrm{~mL}$, is comparable to the $0.14 \mathrm{~mL}$ drip volume reported for Père Noël cave (Genty \& Deflandre 1998) and is therefore appropriate for the natural cave environment.

This combination of peristaltic pump tubing type, pump speed (15 rpm) and drip volume produces average drip rates of $1.6 \pm 0.1,5.8 \pm 0.2$ and $10.4 \pm 0.5 \mathrm{drips} / \mathrm{min}(2 \sigma, n=30)$ for the 'slow', 'medium' and 'fast' drip rate experiments. This corresponds to average flow rates of $0.13,0.67$ and $1.29 \mathrm{~mL} / \mathrm{min}$ and average volumes of solution flowing over the growth plates of 1.8, 6.4 and $11.1 \mathrm{~L}$ during the course of a 7 day experiment.

\section{Precipitation environment}

The drip solution is pumped into a custom made Plexiglas container, designed to host the seeded glass plates and the solution drips feeding them at the required temperature, humidity and $\mathrm{pCO}_{2}$ levels. An annotated photograph is available in figure 2.

Within the confines of the experimental setup the container height was maximized and volume was minimized to achieve a large drip height whilst minimizing the volume of air needing to be brought to temperature. Preexperimental tests revealed that a minimum drip height of $250 \mathrm{~mm}$ is required (with our drip volume of 0.11 $\mathrm{mL}$ ) to shatter the drop on impact with the glass plate. This shattering results in a larger growth surface area and a thinner solution film, which is more representative of the majority of natural stalagmites and which promotes $\mathrm{CO}_{2}$-degassing, therefore increasing growth of calcite. Plexiglas panels, extending $50 \mathrm{~mm}$ above each glass plate, protect against cross-contamination.

Glass plates are placed on in-built supports, all tilted at the same angle of 12 , to prevent the thick solution films that form on horizontal plates as a result of surface tension. This choice of angle is a compromise between minimizing the surface area of ponded solution at the lower end of the glass plate (by increasing the angle of inclination) and maximising the residence time of the solution on the plate (by decreasing the angle of inclination and increasing drip height). The emphasis was on consistency between experiments rather than on investigating the effect of varying angles of inclination on stalagmite chemistry. The morphology of the top of 
natural stalagmites is itself variable and depends on factors such as drip height, drip rate and solution $\mathrm{SI}_{\mathrm{CaCO}_{3}}$. Some degree of ponding is inevitable as the solution reaches the lower edge of the glass plate. In this setup, ponding occurs within an area of the slide referred to here as the ponded zone (figure 3).

$\mathrm{CO}_{2}$ levels within the precipitation container are maintained below $2500 \mathrm{ppm}$ by pumping temperature-adjusted, pre-humidified laboratory air through the container to flush out degassed $\mathrm{CO}_{2}$. Temperature adjustment is achieved by feeding this flow of air through coiled copper piping immersed in the water bath. Pre-humidification is achieved by bubbling the air supply through deionized water, using a gas wash bottle. Solution dripping off the plates, prior to being removed by the peristaltic pump, also adds to the humidity level. The volume of gas pumped through the precipitation container was increased from $200 \mathrm{~L} /$ hour, for the 7 and $15^{\circ} \mathrm{C}$ experiments, to $300 \mathrm{~L} /$ hour for the $25^{\circ} \mathrm{C}$ experiments and finally to a maximum of $400 \mathrm{~L} /$ hour for the $35^{\circ} \mathrm{C}$ experiments. This was necessary to maintain $\mathrm{CO}_{2}$ levels below the target level $(2500 \mathrm{ppm})$ in the face of faster degassing, but had the unfortunate side effect of decreasing humidity levels from $95 \%$ for the $7^{\circ} \mathrm{C}$ experiment, to a minimum of $73 \%$ for the $35^{\circ} \mathrm{C}$ experiment.

\section{Growth substrate, seeding and sample division}

Calcite is grown on glass plates $(76 \times 52 \mathrm{~mm})$ placed on supports at the bottom of the precipitation container. Prior to the experimental run, seed $\mathrm{CaCO}_{3}$ was grown on top of the glass plate to aid nucleation of sample calcite. This seed carbonate was grown in a beaker-type experimental setup. Sixteen glass plates were seeded simultaneously in a polypropylene container. The growth solution was produced by dissolving $0.675 \mathrm{~g}$ Johnson Matthey Specpure calcite in $2000 \mathrm{ml} 18 \mathrm{M} \Omega$ deionized water $\left(3.37 \mathrm{mM} \mathrm{Ca}\right.$ ), doped with $\mathrm{Eu}\left(1.4 * 10^{-5} \mathrm{mM}\right)$ in a $100 \% \mathrm{CO}_{2}$ environment $\left(\mathrm{SI}_{\mathrm{CaCO}_{3}}=-1.25\right)$. Following immersion of the glass plates in the growth solution, the solution was allowed to degas and equilibrate with atmospheric $\mathrm{CO}_{2}$ levels over the course of five days. $\mathrm{CaCO}_{3}$ became increasingly saturated as $\mathrm{CO}_{2}$ degassed and precipitated as a fine coating on the glass plates.

Based on SEM imagery (figure 5) the seed material is dominated by well-defined calcite rhombs, the largest of which approach $100 \mu \mathrm{m}$ in length and also contain a minor amount of aragonite needles and perhaps some minor vaterite. Precipitating $<100 \%$ calcite with this seed precipitation method agrees with the findings of Kim \& O'Neil (1997) who indicate that a mixture of calcite and vaterite is obtained when forming calcium carbonate from $\mathrm{CO}_{2}$-dissolved calcite left to degas slowly. Using a nucleation seed in the stalagmite growth experiment that consists of a mixture of calcium carbonate polymorphs is favourable to using no seed, simple glass frosting (Mickler et al. 2006) or artificial substrates such as glass fiber (Wiedner et al. 2008) because 
seeded growth is more representative of natural growth conditions and more specifically because the presence of seed material closely matched to the precipitating material reduces the energy barrier required for solid precipitation to occur (Steefel, 1990; Stumm \& Morgan, 1996; Lin, 2005).

Europium doping of the seed growth solution is used to distinguish between seed and sample materiel in postexperimental measurements. Eu was chosen because of its affinity for the calcite crystal lattice (Lakshtanov \& Stipp 2004, Terakado \& Masuda 1988), because of its low blanks and because it was not of direct interest in subsequent growth experiments. Seed carbonate Eu was reasonably constant with $4.6 \%$ variation (2 s.d.) in $\mathrm{Eu} / \mathrm{Ca} a_{\text {seed }}$ between the 16 glass plates.

For the purpose of sample retrieval, the plates were subdivided into areas as per figure 3 . The seed calcite grown within the 'ponded zone' of each plate, was scraped off prior to stalagmite experiments and used for determination of $E u / C a_{\text {seed }}$ and $\delta^{18} O_{\text {seed }}$ ratios to characterize the seed composition of each plate. Prior to experimental growth, the plates were weighed on a Sartorius Genius balance, external precision $\pm 22 \mu g$ ( 2 s.d.; $n=43)$, to establish the pre-experiment plate mass. On completion of an experiment, the plates were rinsed carefully (to avoid the adsorption of ions remaining in the drip solution) with a small amount of deionized water, dried overnight at $60 C$, allowed to equilibrate with air temperature and then reweighed to establish growth mass.

\section{Temperature control}

The dissolution \& precipitation chambers and the flush-gas copper piping were all immersed in a large, insulated, 110L water bath (polypropylene water tank with added insulation). Heat was supplied by two C10 Haake immersion circulators with quoted temperature accuracy of $\pm 0.04 C$, fitted to the top of the water bath. Heat was removed using an 'Applied Thermal Control' chiller, model ' $\mathrm{K}$ ', plumbed into a heat exchange unit immersed at the bottom of the water tank. Water circulation, for uniform temperature distribution, was achieved with the circulator function of the two $\mathrm{C} 10$ water heaters with an additional submerged, water pump to improve vertical mixing. This setup ensured stable temperature control in the precipitation vessel at both extremes of the temperature range $(7.1 \pm 0.1$ and $34.9 \pm 0.2 C$ respectively, as determined by temperature logging in the precipitation container).

\section{Establishing growth mass, percentage calcite precipitated}

Growth mass is reported here rather than growth rate, which would require additional measurement of growth surface area. Assessing the surface area of carbonate on the slide is not straightforward because of the relatively 
low coverage of the glass plate with $\mathrm{CaCO}_{3}$. The surface area will also change through the course of the experiments. Because the experimental setup is identical in all experiments, however, surface area is also similar, so that growth mass from the various experiments can be readily compared. The percentage of calcite precipitated $(\% \mathrm{cp})$ is calculated as $\frac{\text { masscalcite precipitated }}{\text { massdissolved calcite flowing overthe plate }}$.

\section{Oxygen stable isotope measurements and associated seed correction}

All synthetic calcite growth takes place on the seed carbonate so $\delta^{18} \mathrm{O}_{\mathrm{CaCO}_{3}}$ measurements constitute a mixture of seed and sample material:

$$
\delta^{18} O_{m i x}=\delta^{18} O_{\text {seed }} * s p+\delta^{18} O_{\text {sample }} *(1-s p)
$$

Where 'sp' is the seed proportion. Rearrangement of 1 provides us with the $\delta^{18} O_{\text {sample }}$ :

$$
\delta^{18} O_{\text {sample }}=\frac{\delta^{18} O_{m i x}-\delta^{18} O_{\text {seed }} * s p}{(1-s p)}
$$

Europium present in the seed and absent from the sample allow the seed proportion to be established as:

$$
\text { Seed proportion }=\frac{(E u / C a)_{\text {mix }}}{(E u / C a)_{\text {seed }}}
$$

Where $E u / C a_{\text {mix }}\left(E u / C a_{\text {seed }}\right)$ is the $E u / C a$ ratio in the mixture of seed \& sample (Eu-doped seed material alone).

Uncertainty on $\delta^{18} O_{\text {sample }}$ is established with Monte Carlo simulations allowing for the known uncertainties on the values for $\delta^{18} O_{m i x}, \delta^{18} O_{\text {seed }},(E u / C a)_{m i x}$ and $(E u / C a)_{\text {seed }}$.

Calculation of expected equilibrium $\delta^{18} \mathrm{O}_{\text {calcite }}$ requires the measurement of $\delta^{18} \mathrm{O}_{\mathrm{H}_{2} \mathrm{O}}$ and values of the fractionation between calcite and water $\left(\alpha_{\text {calcite-water }}\right)$ as a function of temperature. We generally use the widely used Kim \& O’Neil (1997) equation for this $\left(\ln \left(\alpha_{\text {calcite-water }}\right)=\frac{18.03}{T}-0.03242\right.$, where $\mathrm{T}$ is temperature in kelvin). Kim \& O’Neil (1997) is not the only study into the equilibrium fractionation factors between calcite and water but the predicted values are in reasonable agreement with other experimental and theoretical results (e.g. Tarutani et al. 1969, O’Neil et al. 1969 and Horita \& Clayton 2007). We discuss the accuracy of these equations later in this paper. 
All oxygen isotope measurements were performed on a Delta V Advantage isotope mass spectrometer fitted with a Kiel IV carbonate device and a Gas Bench II. The Kiel device converted the carbonates to $\mathrm{CO}_{2}$ with $100 \% \mathrm{H}_{3} \mathrm{PO}_{4}$ (McCrea, 1950). The relative ${ }^{18} \mathrm{O} /{ }^{16} \mathrm{O}$ values $\left(\delta^{18} \mathrm{O}\right)$ of carbonate are expressed in per mil relative to VPDB on a normalized scale such that the $\delta^{18} O$ of NBS-19 is $-2.2 \%$ and the $\delta^{18} O$ of NBS-18 is $-23.2 \%$. External error $(0.08 \%, \mathrm{n}=62)$ is calculated from repeat measurements of NBS-18 and NBS-19. We assume that the phosphoric acid - carbonate fractionation is the same for NBS-19 and our calcite samples (Coplen, 1996). Water was analyzed for $\delta^{18} O$ on the Gas Bench II with the method described in Nelson (2000). Iso-Analytical Limited standards IA-RO52 and IA-RO54 were used for two-point linear normalization with IARO52 $=-19.64 \pm 0.23 \%$ and IA-RO54 $=0.56 \pm 0.23 \%$ relative to VSMOW2. External error is calculated and accuracy was checked from repeat measurements of Iso Analytical standard IA-RO53, with our two-point normalized results $\left(\delta^{18} \mathrm{O}_{\mathrm{H}_{2} \mathrm{O}}=-10.21 \pm 0.14, \mathrm{n}=21\right)$ within error of Iso-Analytical Limited laboratory results $\left(\delta^{18} O_{H_{2} O}=-10.18 \pm 0.20, \mathrm{n}=20\right)$. For carbonates and waters, results are expressed on the same normalized scale such that $\delta^{18} O$ of SLAP2 reference water is $-55.5 \%$.

\section{Results}

At all three drip rates, there is a substantial increase in growth mass with temperature (table 3), with an average eight-fold increase between 7 and $35^{\circ} \mathrm{C}$ (figures 6 and 9). At the lower end of the temperature range, drip rate has an insignificant effect on growth mass. A drip rate effect becomes significant at higher temperatures however, with a peak in growth mass at intermediate drip rate. There is a monotonic increase in \%cp with decreasing drip rate, (figure 6, subplot b).

SEM analysis of the seed and sample growth shows overgrowth of sample calcite on both calcite and aragonite seed (e.g. images D and F of figure 4) and the dominance of calcite sample growth (all of the seed carbonate is covered with calcite overgrowth).

There is a strong decrease of $\delta^{18} O_{\text {calcite }}$ with increase in temperature (figure 7), broadly in line with the expected relationship between $\alpha_{\text {calcite-water }}$ and temperature established by previous work (e.g. Kim \& O’Neil 1997). There is however a steady divergence of $\delta^{18} O_{\text {calcite }}$ above predicted equilibrium values as temperature increases (figure 8). This divergence is less pronounced at higher drip rates (figure 8). There is no clear relationship between $\delta^{18} O_{\text {calcite }}$ and location on the slide, i.e. splash zone versus flow zone versus ponded zone, (figure 7). 
Carbon isotopes, although measured, are not presented here because the unknown mixture of carbon from the dissolved $\mathrm{CaCO}_{3}$ and $\mathrm{CO}_{2}$ in the initial solution lead to inconsistent starting conditions between experiments.

\section{Discussion}

\subsection{Controls on stalagmite growth rate}

These experiments demonstrate a clear positive relationship between carbonate growth mass and temperature, and a more complex relationship between growth mass and drip rate. In this section we discuss the relative importance of these two controls on growth rate and the implications for the natural cave environment.

Over the range of temperatures and drip rates covered by this study, temperature is the dominant factor in controlling growth mass. Stepwise regression demonstrates a good fit between growth rate and temperature, with consideration of drip rate not significantly improving the fit. However, it is the combination of drip rate's minimum impact at low temperatures, combined with the non-linear relationship at higher temperatures, that results in the apparent lack of significance of drip rate in linear regression studies.

In natural speleothem studies, variation in growth mass will result from small changes in temperature and from relatively small changes in average drip rate. A function that describes the relationship between growth mass, drip rate and temperature for a solution with an initial $S I_{\text {calcite }}$ of 0.34 is:

$$
\text { dailygrowthmass }=1.254+1.478 * 10^{-9} * e^{0.0679 T}+\left(e^{0.00248 T}-2\right) *\left(-0.779 d \_r^{2}+10.05 d \_r+11.69\right)
$$

Where $\mathrm{T}$ is the temperature in kelvin and d_r is the drip rate in drips $\min ^{-1}$.

Output from this function is illustrated in figure 9 and allows useful growth mass interpolations for temperature and drip rate variations at the experimental conditions (i.e. for a non-degassed solution with $\mathrm{pH}=6.9$ and $\left.S I_{\text {calcite }}=0.34\right)$. In the natural setting, other environmental variables (e.g. saturation index, cave $p C \mathrm{O}_{2}$, stalagmite morphology) will cause deviations from this laboratory configuration but these results nevertheless provide some indication of the influence of temperature and drip rate on expected linear extension rates.

One of the implications of these empirical results is that growth mass does not follow a simple linear increase with increasing drip rate as is sometimes considered the case. The reason for this is the competition between 
two processes: i) the supply rate of new ions to the speleothem surface, and ii) the percentage of calcite that can be precipitated in a given period of time. With reference to (ii) it is evident that the percentage of calcite precipitated (\%cp) from each drop increases with residence time on the speleothem surface (figure 6). It is this competition between supply rate and \%cp which causes the quadratic relationship between drip rate and growth mass, with optimal growth mass for intermediate drip rates.

At low temperature, drip rate has a very small influence on growth mass (figure 9). This is caused by lower reaction rates at low temperature, including the lower rate of $\mathrm{CO}_{2}$-degassing. The slower degassing- and precipitation-rates result in smaller absolute differences over the same drip intervals. This is important as it simplifies the palaeoclimatic interpretation of growth mass variation in low temperature settings. Ideally, this would leave temperature as the sole or dominant control although, in practice, other factors such as saturation index are likely to play some role.

\subsection{Conditions for avoidance of evaporative and chemical disequilibrium effects}

For the purposes of identifying suitable samples for palaeoclimate work and for interpreting $\delta^{18} O_{\text {stalagmite }}$ of existing records, it is important to understand the processes that cause $\delta^{18} O_{\text {stalagmite }}$ to shift away from isotopic

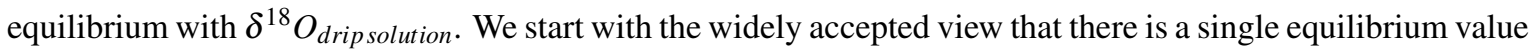

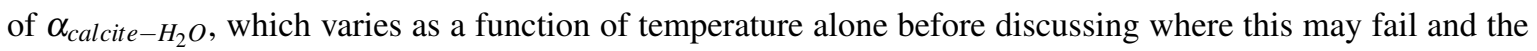
implications of variable $\alpha_{\text {calcite }-\mathrm{H}_{2} \mathrm{O}}$ applying to calcite precipitation in many natural settings.

There is clear disagreement between published predicted equilibrium $\alpha_{\text {calcite }-\mathrm{H}_{2} \mathrm{O}}$ relationships. In addition, there are deviations between any one of these published relationships and the experimental results of this study (figure 8). For the higher temperature experiments of this study, there are statistically significant differences between the experimental $\delta^{18} O_{\text {stalagmite }}$ of the different drip rates. We start by examining the processes behind these inter-drip rate differences, which must lead to one or more of the drip rate results deviating from equilibrium. We then build on this understanding of the oxygen isotope incorporation to discuss the discrepancies between published values of $\alpha_{\text {calcite }-\mathrm{H}_{2} \mathrm{O}}$.

For the higher temperature experiments $\left(25\right.$ and $\left.35^{\circ} \mathrm{C}\right)$ there are significant differences between the results for the different drip rates, with higher $\delta^{18} O_{\text {stalagmite }}$ for the lower drip rates (figure 8). Two processes that cause $\delta^{18} O_{\text {calcite }}$ and $\delta^{18} O_{\text {solution }}$ to shift to higher values are rapid depletion of the dissolved inorganic carbon reservoir (rapid DIC-depletion) and evaporation respectively. These processes of rapid DIC-depletion and evaporation and the scale of their impact on $\delta^{18} O_{\text {calcite }}$ are investigated in the next section. In either 
case, however, these processes cause shifts towards higher $\delta^{18} O_{\text {stalagmite }}$ than that predicted from equilibrium $\alpha_{\text {calcite-'infiltratedmeteoricsolution' }}$ and this behaviour becomes more pronounced as the solution spends longer on the surface of the stalagmite, allowing more time both for $\mathrm{CO}_{2}-$ degassing/DIC-depletion and for evaporation.

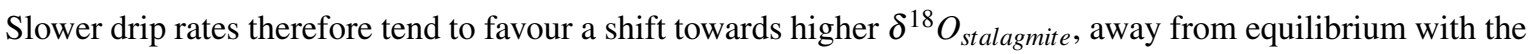
original drip solution, due to the resulting increase in water residence time on the growth surfaces. This is somewhat counter-intuitive - kinetic effects are normally associated with faster growth and therefore perhaps with faster drips. But in the cave situation the important thing is how long each drip has to deplete the bicarbonate reservoir and/or evaporate before it is removed from the growth region. These shifts to higher $\delta^{18} O$ become more pronounced as temperature increases simply because both $\mathrm{CO}_{2}$-degassing and evaporation rates increase with temperature. This study indicates clearly that to avoid evaporation- and DIC-depletion-effects on the $\delta^{18} O$ of calcite, required for straightforward palaeoclimate interpretation of stalagmite records, it is best to select situations where drip-rates are fast and where temperatures are low.

\subsection{Sources of disequilibrium}

It is worth considering which of the two processes commonly invoked to cause shifts to higher $\delta^{18} O_{\text {stalagmite }}$ (Hendy, 1971) dominate in these experiments because understanding the relative importance of rapid DICdepletion and evaporation will help with selection of appropriate caves for palaeoclimate work. Quantifying the amount of evaporation or unbuffered DIC-depletion is currently not possible for past growth and therefore selecting a sample with minimal impact from these two processes will increase the degree to which $\delta^{18} O_{\text {stalagmite }}$ reflects changes in the infiltrated meteoric solution rather than changes in the degree of disequilibrium fractionation.

In the case of rapid DIC-depletion, $\delta^{18} O$ becomes fractionated when the DIC reservoir is depleted so rapidly (by $\mathrm{CO}_{2}$-degassing and $\mathrm{CaCO}_{3}$-precipitation) that $\delta^{18} \mathrm{O}$ in the carbonate species cannot maintain equilibrium with $\mathrm{H}_{2} \mathrm{O}$. More specifically, it is the dehydration of $\mathrm{HCO}_{3}^{-}$and the hydration of $\mathrm{CO}_{2(a q)}$ (both required for isotopic equilibration) which cannot keep pace with DIC-loss (e.g. Mills \& Urey 1940, Pinsent \& Roughton 1951 , Hendy 1971). In the case of evaporation of water, $\delta^{18} O_{\text {solution }}$ increases due to the preferential loss of ${ }^{16} \mathrm{O}$ atoms from solution to vapour. To distinguish between these effects we use theoretical models from the literature.

Two models have previously been presented to explain the effects of rapid DIC-depletion. Hendy (1971) models the isotopic fractionation between bicarbonate ions and $\mathrm{CO}_{2}(a q)$ as a kinetic-isotopic-fractionation 
effect, where fractionation is induced by differences in rate constants for molecules containing ${ }^{16} \mathrm{O}$ and ${ }^{18} \mathrm{O}$ during the forward and backward reactions involved in calcite growth. The resulting difference of $\delta^{18} O$ from equilibrium $\left(\Delta^{18} O\right)$ is defined as:

$$
\Delta^{18} O \approx 1000 * \frac{k_{A 1^{\prime}}}{3} *\left(1-\frac{k_{A 3^{\prime}}+k_{A 4^{\prime}}}{k_{A 1^{\prime}}}\right) * t
$$

where the ' $\mathrm{k}$ ' terms are rate constants of specific isotopologues with different combinations of ${ }^{18} \mathrm{O}$ and ${ }^{16} \mathrm{O}$ atoms (Hendy 1971). An issue with this approach is that the rate constant ratios $k_{A 2^{\prime}} / k_{A 1^{\prime}}, k_{A 3^{\prime}} / k_{A 1^{\prime}}$ and $k_{A 4^{\prime}} / k_{A 1^{\prime}}$ are unknown and instead only minimum values are obtained from high temperature limiting reaction rates.

Mickler et al. (2006), on the other hand, models the disequilibrium chemically rather than isotopically, as a Rayleigh distillation of the original bicarbonate during loss of bulk product from solution. The bulk product lost from the carbonate pool is the combination of $\mathrm{CaCO}_{3}, \mathrm{CO}_{2}(\mathrm{~g})$ and $\mathrm{H}_{2} \mathrm{O}(\mathrm{l})$ that result from the calcite precipitation reaction:

$$
\mathrm{Ca}^{2+}+2 \mathrm{HCO}_{3}^{-} \rightleftharpoons \mathrm{CaCO}_{3}+\mathrm{CO}_{2}(\mathrm{~g})+\mathrm{H}_{2} \mathrm{O}(\mathrm{l})
$$

The Rayleigh equation requires a fractionation factor between the reactants and the three products, which is defined as (Mickler et al. 2006):

$$
\alpha_{\text {bulk product }-\mathrm{HCO}_{3}^{-}}=\frac{2}{6}\left(\alpha_{\mathrm{CO}_{2}(g)-\mathrm{HCO}_{3}^{-}}\right)+\frac{3}{6}\left(\alpha_{\text {calcite }-\mathrm{HCO}_{3}^{-}}\right)+\frac{1}{6}\left(\alpha_{\mathrm{H}_{2} \mathrm{O}-\mathrm{HCO}_{3}^{-}}\right)
$$

Where the coefficients are the proportion of oxygen removed from the DIC reservoir by each of the three products and the values of $\alpha$ are published fractionation factors from the literature.

To estimate the influence of rapid DIC-depletion on the enrichment of $\delta^{18} O_{\text {calcite }}$, we apply the Rayleigh distillation model of Mickler et al. (2006) to our experimental context. We present this calculation only for the $25^{\circ} \mathrm{C}$ situation, which applies directly to the widest range of published fractionation factors. We use updated values of $\alpha$ compared with those used by Mickler et al. (2006), with $\alpha_{\mathrm{CO}_{2}(g)-\mathrm{HCO}_{3}^{-}}=1.0094, \alpha_{\text {calcite }-\mathrm{HCO}_{3}^{-}}=$ 0.9971 and $\alpha_{\mathrm{H}_{2} \mathrm{O}-\mathrm{HCO}_{3}^{-}}=0.9695$, derived from $\alpha_{\mathrm{HCO}_{3}^{-}-\mathrm{H}_{2} \mathrm{O}}=1.0315$ (Beck et al. 2005), $\alpha_{\mathrm{CO}_{2}(g)-\mathrm{H}_{2} \mathrm{O}}=$ 1.0412 (Brenninkmeijer et al. 1983) and $\alpha_{\text {calcite }-\mathrm{H}_{2} \mathrm{O}}=1.0290$ (Dietzel et al. 2009, for $\log \mathrm{R}=2.06$ ). This gives $\alpha_{\text {bulk product }-\mathrm{HCO}_{3}^{-}}=0.9966$, compared with 0.9935 used by Mickler et al. (2006). We note however, 
that substituting $\alpha_{\mathrm{HCO}_{3}^{-}-\mathrm{H}_{2} \mathrm{O}}$ from the value of Usdowski \& Hoefs (1993) to that of Beck et al. (2005) and $\alpha_{\text {calcite }-\mathrm{H}_{2} \mathrm{O}}$ from the value of Kim \& O'Neil (1997) to that of Dietzel et al. (2009) has only a minor impact on the degree of $\delta^{18} \mathrm{O}$ enrichment in this context and does not alter the conclusions reached in section 4.4. The fractionation factor $\left(\alpha_{\text {bulk product }-\mathrm{HCO}_{3}^{-}}\right)$is applied to the standard Rayleigh distillation equation (Faure \& Mensing 2005):

$$
\frac{\delta^{18} \mathrm{O}_{\mathrm{HCO}_{3}^{-}}^{t}+10^{3}}{\delta^{18} \mathrm{O}_{\mathrm{HCO}_{3}^{-}}^{0}+10^{3}}=f^{\alpha_{\text {bulk product }-\mathrm{HCO}_{3}^{-}}-1}
$$

to obtain the difference between $\delta^{18} \mathrm{O}_{\mathrm{HCO}_{3}^{-}}^{0}$ and $\delta^{18} \mathrm{O}_{\mathrm{HCO}_{3}^{-}}^{t}$ with fraction, f, of bicarbonate remaining in solution. The value of $\mathrm{f}$ is known from the $\% \mathrm{cp}$ for the three $25^{\circ} \mathrm{C}$ experiments, combined with the stoichiometric requirement that two moles of the carbonate species are removed for each mole of calcium. This enables calculation of a maximum kinetic effect assuming that no exchange occurs between bicarbonate and $\mathrm{H}_{2} \mathrm{O}$ during carbonate growth. Any exchange of oxygen between $\mathrm{H}_{2} \mathrm{O}$ and $\mathrm{HCO}_{3}^{-}$will lead to calcite that is closer to equilibrium. The rate of this process can be assessed using the half-lives of oxygen isotope equilibration published by Hendy (1971). These half-life values are $\approx 470$ seconds at $20^{\circ} \mathrm{C}$ and $\approx 1050$ seconds at $10^{\circ} \mathrm{C}, \mathrm{pH} 8$. Linear extrapolation was used to obtain half-lives applicable to $25^{\circ} \mathrm{C}$, which were applied to a standard exponential decay equation, $N_{t}=N_{0} e^{-\lambda t}$, where $\lambda=\frac{\ln (2)}{t(1 / 2)}$.

To estimate the maximum effect due to the second process, evaporation, we calculate the maximum amount of $\mathrm{H}_{2} \mathrm{O}$ that can be lost before calcite growth and therefore the possible impact on $\delta^{18} \mathrm{O}$ by Rayleigh distillation (Wiedner et al. 2008):

$$
\% \mathrm{H}_{2} \mathrm{Oloss}=\Delta \rho * \frac{f}{r}
$$

where:

$\mathbf{r}$ is the flow rate of solution $(\mathrm{g} / \mathrm{min})$ over the glass plate, which increases with drip rate.

f is the flow rate of the flushing gas (L/min). $200 \mathrm{~L} / \mathrm{min}$ at 7 and $15^{\circ} \mathrm{C} .300 \mathrm{~L} / \mathrm{min}$ at $25^{\circ} \mathrm{C}$ and $400 \mathrm{~L} / \mathrm{min}$ at $35^{\circ} \mathrm{C}$.

$\rho$ is the mass of water in air for a given temperature (g/L). Values from HyperPhysics(webpage) (2009).

$\Delta \rho=\rho *(100-R H \%)$ is the mass of water required to evaporate to raise a given relative-humidity (RH\%) to $100 \%$. 
These calculations indicate maximum deviations of $\delta^{18} O$ from equilibrium induced by rapid DIC-depletion and evaporation at $25^{\circ} \mathrm{C}$ and are plotted in figure 10.

At slow drip rates, observed fractionation deviates from that expected from Kim \& O’Neil (1997) by 1.0\% . The magnitude of this deviation is significantly greater than can be explained by kinetic fractionation produced by rapid DIC-depletion (figure 10) indicating that evaporation is playing a dominant role in the deviation from equilibrium. This suggests that, for natural samples, the effect of evaporation cannot be ignored and it is important to monitor relative humidity and airflow. In addition to assessing modern-day conditions, samples should be retrieved from cave settings that favour high relative humidity throughout the growth history of the samples growing within. Cave morphologies that favour pooled or flowing water and reduced airflow within the sample chamber are preferable.

\subsection{Which equilibrium fractionation is correct?}

These experiments also allow assessment of which of the various equations for equilibrium fractionation between calcite and water is most accurate. Although the Kim \& O’Neil (1997) equation is the most widely used equilibrium equation, some recent work has called its accuracy into question based on natural (Coplen 2007) and laboratory (Dietzel et al. 2009) carbonates. At high drip rates, lower water residence times in the reaction vessel and lower \%cp do not allow for significant effects due to either evaporation or rapid DIC-depletion (figure 10). At 10.4 drips/min and $25^{\circ} \mathrm{C}$, for instance, the maximum possible disequilibrium by combining the two processes is only $0.15 \%$. The observed $\delta^{18} O$, however, is $0.34 \%$ higher than expected from the Kim \& O’Neil (1997) equation (figure 10), suggesting that this equation is not correct. Coplen (2007) argued for a higher $\alpha_{\text {calcite-water }}$ and suggested that lower fractionation factors between calcite and water obtained in other settings (e.g. Kim \& O'Neil 1997) may be due to a kinetic effect of surface entrapment of ${ }^{16} \mathrm{O}$ during mineral growth. More recent experimental results by Dietzel et al. (2009) have supported this argument and demonstrated clear relationships between growth rate and $\alpha_{\text {calcite-water }}$. For instance, at $25^{\circ} \mathrm{C}$ and $\mathrm{pH} 8.3$, the relationship between growth rate $\left(\mathrm{R}, \mu \mathrm{molm}^{-2} h^{-1}\right)$ and $\alpha_{\text {calcite-water }}$ is defined by Dietzel et al. (2009) as 
with $\alpha_{\text {calcite-water }}$ decreasing with increasing growth rate. Although the experimental context of the Dietzel et al. (2009) experiments is different to ours (i.e. beaker-type experiments rather than faster degassing thin solution film experiments in our case), the surface entrapment effect should be universal, therefore we use equation 10 from Dietzel et al. (2009) to test the growth rate adjusted $\alpha_{\text {calcite }-H_{2} O}$ with our experiments. Equation 10, derived for $\mathrm{pH} \mathrm{8.3,} \mathrm{applies} \mathrm{here} \mathrm{because} \mathrm{the} \mathrm{initial} \mathrm{drip} \mathrm{solution} \mathrm{at} \mathrm{pH} 6.9$ is expected to degas and reach $\mathrm{pH} \sim 8.3$ within several seconds (Dreybrodt 2008; Johnson et al. 2006). To derive a growth rate adjusted $\alpha_{\text {calcite- } \mathrm{H}_{2} \mathrm{O}}$ we first convert $\Omega_{\text {calcite }}$ to $\log \mathrm{R}$ using the strong relationship between these variables in Dietzel et al. 2009. For a saturation ratio of 2.2, at which drips enter our experiment, $\log \mathrm{R}$ is expected to be 2.06 and $\alpha=1.0289$. The associated value of $\delta^{18} O_{\text {calcite }} \sim-8.3 \%$ fits well with our measurements (figure 10). Based on this calculated value of $\alpha_{\text {calcite-water }}$ (figure 10), our fastest drip rate experiment (10.4 drips $/ \mathrm{min}$ ) appears to be unaffected by evaporation or rapid DIC-depletion. With decreasing drip rate, the experimental calcite is increasingly affected by evaporation and DIC-depletion effects.

This study therefore supports the assertion of Coplen (2007) that the equilibrium $\alpha_{\text {calcite-water }}$ is significantly higher than that of Kim \& O'Neil (1997) and that observed $\alpha_{\text {calcite-water }}$ values are lowered due to surface entrapment of ${ }^{16} \mathrm{O}$ (Dietzel et al. 2009). The implication of these results is that in the cave setting (and other natural environments) the applicable $\alpha$ is a function of both temperature and growth rate. This conclusion may have implications for existing stalagmite studies. Stalagmites from Spannagel Cave in Austria (Mangini et al. 2005), for instance, form slowly and with an observed modern $\alpha$ noticeably higher than predicted by Kim \& O'Neil (1997) but close to that of Coplen (2007). Even for faster growing samples such as those in Villars cave (Genty 2008) the Coplen (2007) value for $\alpha_{\text {calcite-water }}$ appears more appropriate and provides a more realistic temperature estimate for the cave. In stalagmites which change their growth rates significantly (e.g. Baldini et al. 2005) it may also be most appropriate to consider a changing $\alpha_{\text {calcite-water }}$ due to growth rate effects.

In calculating the effect of rapid DIC-depletion on $\delta^{18} O_{\text {stalagmite }}$, we only considered the incorporation of $\mathrm{HCO}_{3}^{-}$into the calcite lattice. There are however studies which suggest that other carbonate species could be incorporated in calcium carbonate. Zeebe (1999) argues that calcite is formed from a mixture of carbonate species in proportion to their relative contribution to the DIC reservoir. At first sight, this hypothesis appears to be invalid in the case of our experiments, as the lower concentration of our solution, compared with that of Kim \& O'Neil (1997) $\left(2.9 \mathrm{mmol} / \mathrm{L}\right.$ instead of $5 \mathrm{mmol} / \mathrm{L}$, table 1), would result in an even lower $\alpha_{\text {calcite- } \mathrm{H}_{2} \mathrm{O} \text { than }}$ that proposed by Kim \& O’Neil (1997), which is harder still to reconcile with the fast drip rate results (figure 10). We should however be wary of comparing the fast-degassing growth environment of seeded, speleothem calcite with the slow-degassing beaker experiments of Kim \& O'Neil (1997). From their experimental results, 
Kim et al. (2006) suggest that $\mathrm{CO}_{3}^{2-}$ is the dominant species precipitated in calcium carbonate, although their experiments relate to aragonite rather than calcite. Having $\mathrm{CO}_{3}^{2-}$ as the dominant species is also incompatible with the Kim \& O'Neil (1997) value of $\alpha_{\text {calcite- } \mathrm{H}_{2} \mathrm{O}}$ because fractionation caused by rapid $\mathrm{CO}_{3}^{2-}$-depletion would force $\delta^{18} O_{\text {stalagmite }}$ towards values that are lower than those of predicted equilibrium, again making it impossible to reconcile with the fast drip rate results (figure 10). Testing whether $\mathrm{CO}_{3}^{2-}$ incorporation is compatible with another equilibrium value of $\alpha_{\text {calcite- } \mathrm{H}_{2} \mathrm{O}}$ is unfortunately not possible with this series of experiments because of the significant degree of evaporation. Similar experiments with no evaporative effect in which increasing, unbuffered DIC-depletion leads to $\delta^{18} O_{\text {stalagmite }}$ lower than equilibrium would be supportive of $\mathrm{CO}_{3}^{2-}$ being the dominant species incorporated into calcite. This has yet to be tested.

\subsection{Limitations of the Hendy test}

The ability to distinguish between equilibrium and disequilibrium $\delta^{18} O_{\text {stalagmite }}$ is an important part of any natural stalagmite study and impacts greatly on the interpretation of the stable isotope measurements. Here we focus on processes operating at the stalagmite surface and therefore whether variation in $\delta^{18} O_{\text {stalagmite }}$ reflects variation in $\delta^{18} O_{\text {infiltratedmeteoric solution }}$ (true in equilibrium growth conditions) or instead reflects variation in the precipitation conditions in the cave (e.g. evaporation of the drip solution, rapid DIC-depletion or change in $S I_{\text {calcite }}$ ). Hendy (1971) outlined fundamental theoretical aspects of oxygen and carbon isotope incorporation in speleothems and detailed why increases in both $\delta^{13} C_{\text {stalagmite }}$ and $\delta^{18} O_{\text {stalagmite }}$ along a given growth band is evidence of disequilibrium speleothem growth. This has subsequently been termed the 'Hendy Test'.

The controlled growth conditions of these experiments illustrate two limitations of the Hendy test: i) a constant $\delta^{18} O_{\text {calcite }}$ along a given growth layer does not indicate equilibrium stalagmite growth (i.e. a sample cannot 'pass' a Hendy test, in agreement with Hendy (1971)) and ii) the Hendy test is based on relative differences in $\delta^{13} \mathrm{C}$ and $\delta^{18} \mathrm{O}$ and therefore has no concept of whether growth axis calcite is in equilibrium. These limitations do not negate the usefulness of the test in detecting disequilibrium growth in samples that show a clear evolution of $\delta^{18} \mathrm{O}$ along a growth band. The $25^{\circ} \mathrm{C}$ results illustrate the first limitation (i), as there is no significant increase in $\delta^{18} O_{\text {stalagmite }}$ with distance from the splash zone yet significant inter drip rate differences, indicating that at least one of the drip rates is fractionated (figure 7). Disequilibrium growth-axis calcite can occur in two general cases, firstly if the drip solution is already fractionated on arrival on the stalagmite surface. This fractionation can arise from rapid DIC-depletion or evaporation from the solution on the stalactite surface. Subsequently, on the stalagmite surface, conditions can be favourable for not failing the Hendy test (i.e. continued DIC-depletion causing $\delta^{13} C_{\text {calcite }}$ to increase, combined with buffering of $\delta^{18} O_{\text {calcite }}$ which ensures constant $\delta^{18} O_{\text {calcite }}$ ), 
whilst maintaining an inherited state of disequilibrium. It is actually more likely for growth layer $\delta^{18} O_{\text {calcite }}$ to remain constant subsequent to substantial degassing and calcite precipitation. Calcite precipitation causes $S I_{\text {calcite }}$ to tend back towards 0, degassing- and growth-rates decrease, thus providing more chance for the oxygen isotope buffering to keep pace with DIC-removal. In a cave setting, measuring the stalactite tip in addition to the top of the stalagmite in actively growing systems can help to test for this scenario. $\delta^{18} O_{\text {stalagmite }}$ $>\delta^{18} O_{\text {stalactite }}$ should be indicative of disequilibrium growth. For this, the modern calcite should be collected on new surfaces (e.g. a glass rod / glass plate setup), so that the calcite precipitated on the stalactite and the stalagmite are known to correspond to the same growth period. For these laboratory experiments, we know that calcite precipitation has not occured prior to the solution arriving on the glass plate (c.f. precautions detailed in section 2). In this case, fractionation is therefore occuring within the splash zone, i.e. on the growth axis. This can occur if the residence time of drip solution on the growth axis surface allows sufficient depletion of the DIC-reservoir to cause fractionated calcite growth, yet insufficient time for oxygen isotope buffering to re-equilibrate the solid with the solution.

Because the Hendy test is based only on relative changes of $\delta^{13} C$ and $\delta^{18} O$, it can also not detect whether the applicable $\alpha_{\text {calcite }-\mathrm{H}_{2} \mathrm{O}}$ has varied through time caused by varying $S I_{\text {calcite }}$, as per Dietzel et al. 2009 findings. If $\alpha_{\text {calcite }-H_{2} O}$ is a function of $S I_{\text {calcite }}$, in addition to temperature, then a proxy for $S I_{\text {calcite }}$ in the drip solution is required to establish its variation, or not, through time.

\section{Conclusions}

This is the first series of laboratory calcite growth experiments that closely mimic the mechanisms of calcite dissolution and precipitation seen during growth of stalagmites. These experiments replicate the cave environment as closely as possible with drip volumes, flow rates, and solution composition typical of natural cave settings. These efforts are important for extrapolation of laboratory experiments to natural cave systems. From the results and the subsequent discussion, we conclude that:

- Temperature has a more significant effect on growth mass than drip rate, particularly at low temperature.

- Elevated $\delta^{18} O_{\text {stalagmite }}$, compared with values expected from $\alpha_{\text {calcite-'infiltrated meteoric solution' }}$, induced by rapid DIC-depletion and evaporation increases with higher temperature and, counter-intuitively perhaps, can also increase with slower drip rate. 
- Fast dripping cold caves are therefore likely to be the most appropriate for palaeoclimate work. Evaporation is the dominant effect moving $\delta^{18} O$ to higher values in these growth conditions. In addition to assessing modern-day conditions, samples should be retrieved from cave settings that favour high relative humidity throughout the growth history of the samples growing within. Cave morphologies that favour pooled or flowing water and reduced airflow within the sample chamber are preferable.

- These experimental measurements of $\delta^{18} O$ suggest that equilibrium fractionation factors are larger than those derived by Kim \& O'Neil (1997), in agreement with the findings of Coplen (2007). $\delta^{18} O$ values lower than those predicted by Coplen (2007) may be explained by a kinetic-isotope effect, which favours incorporation of ${ }^{16} \mathrm{O}$ over ${ }^{18} \mathrm{O}$ in the solid carbonate due to surface entrapment, in accordance with the results of Dietzel et al. (2009).

- Samples can pass the Hendy test and still be out of equilibrium for $\delta^{18} O$.

\section{Acknowledgements}

We thank Derek Preston and Dave Pinchin for help in production of the experimental apparatus; and Kathleen Johnson, Alan Matthews and Lara Kalnins for discussion. Finally we thank the three anonymous reviewers for their contribution to an improved manuscript. This work was funded by NERC grant NE/G003416/1. 


\section{Calcite growth overview}

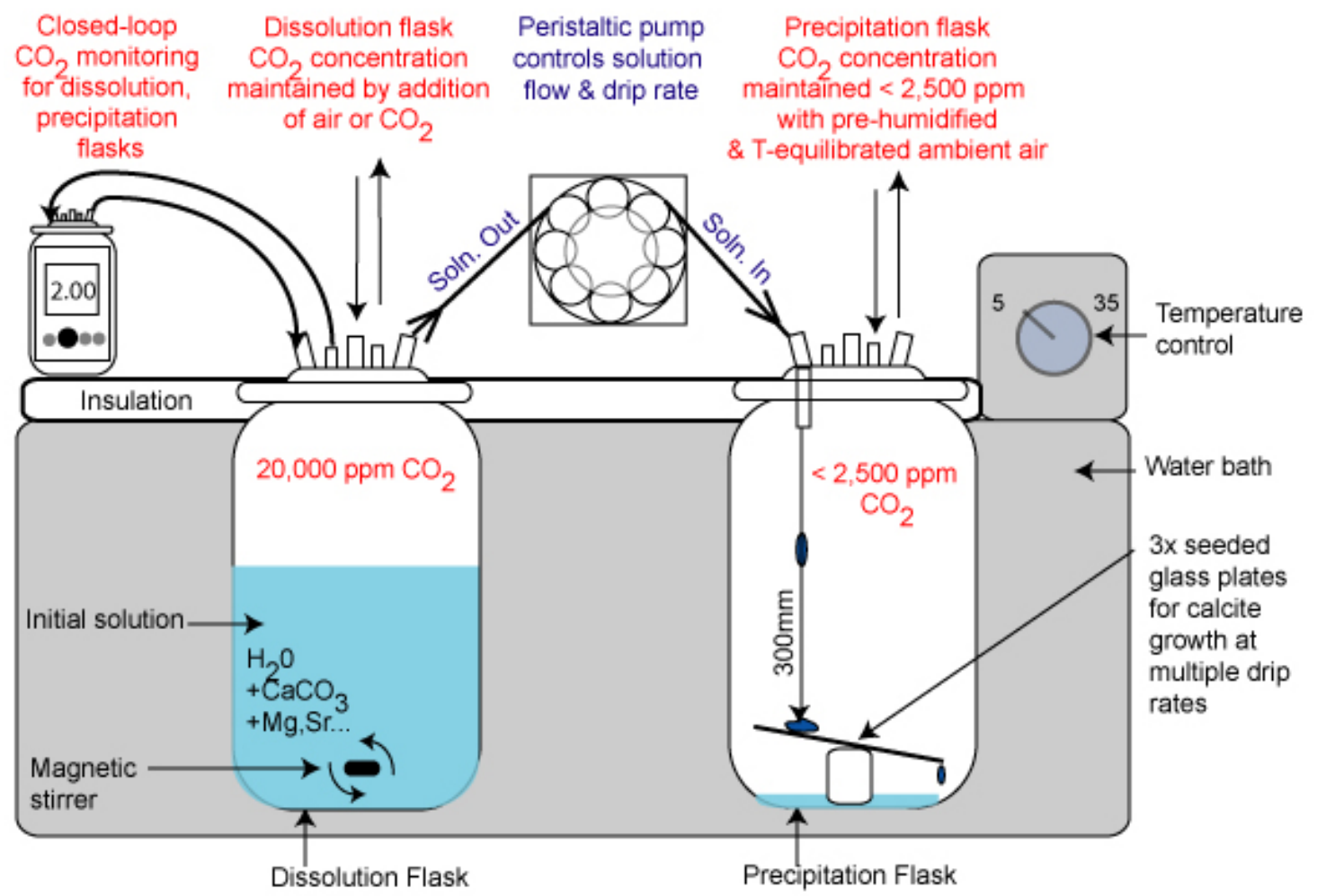

Figure 1: Cartoon overview of the experimental setup. $\mathrm{CO}_{2}$-monitoring can be conducted on the dissolution flask or the precipitation flask in the same manner. 


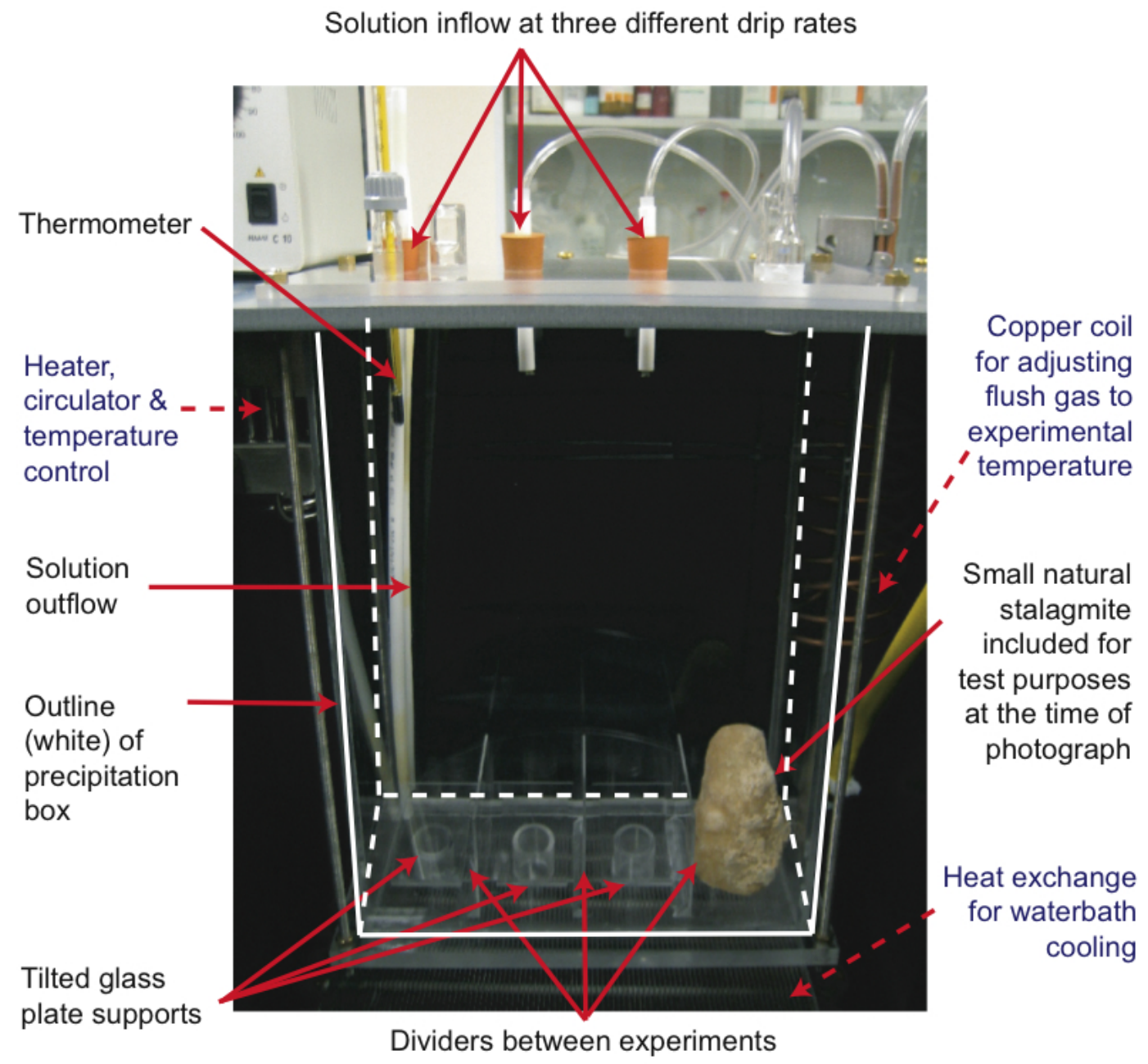

Figure 2: Annotated photograph of the precipitation environment. The white line marks the outline of the precipitation box, which is immersed in a large water bath for temperature control. Regular text and continuous arrows describe items contained within the precipitation box. Italics and dashed arrows depict items outside the precipitation box but within the water bath. 
A Plan View

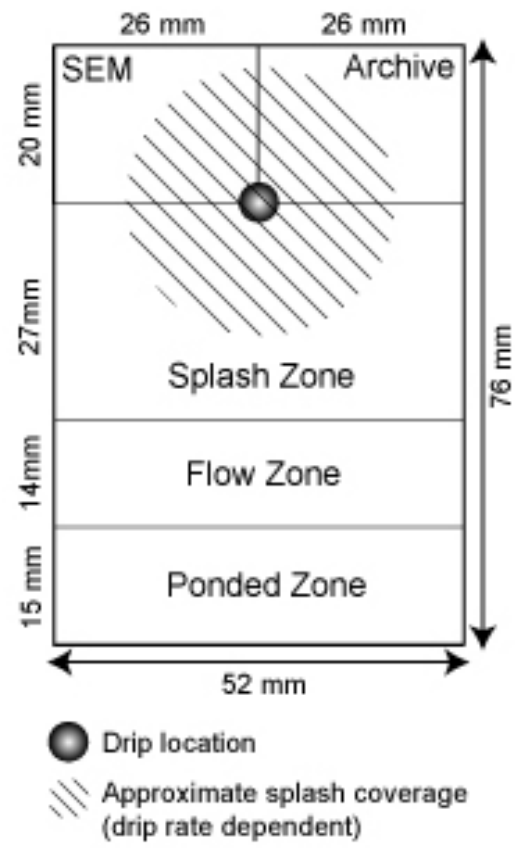

B Profile View

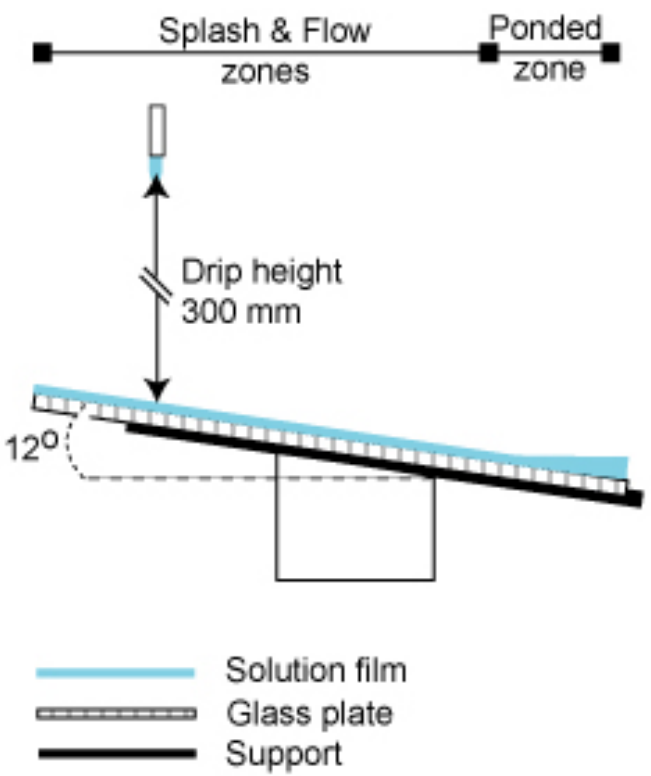

Figure 3: A: Plan view of the glass plate illustrating zones used for sample division. The filled circle is the point where the drip makes contact with the glass plate. The hashed circle is an approximate indication of the area covered by the splash generated by each drip, this varies with drip height and drip rate. 'SEM' is a portion of glass plate dedicated to in situ optical and scanning electron microscopy of the seed and sample crystals. 'Archive' contains in situ growth calcite for archive purposes. Down flow of these, the plate is divided into three areas to allow the evolution of calcite chemistry to be assessed. The 'splash zone' contains a large percentage of the 'splashed' solution; the 'flow zone', receives a larger amount of solution flowing down from the 'upstream' areas; the 'ponded zone' has greater solution depth due to surface tension as the solution reaches the lower edge of the glass plates. B: Profile view of the glass plate as positioned within the precipitation box. 


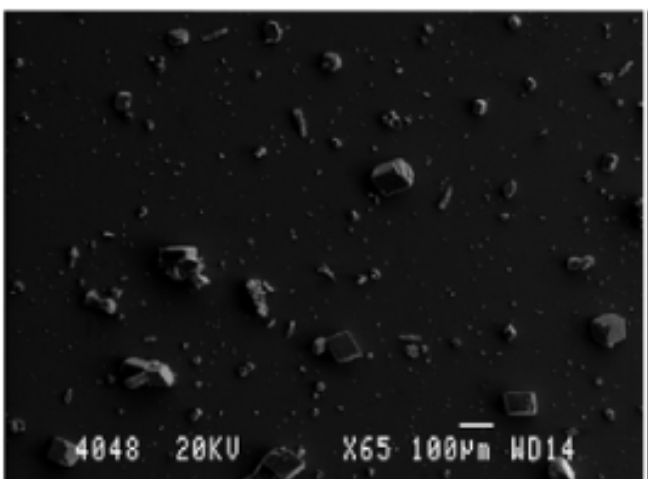

A: Seed, $x 65$

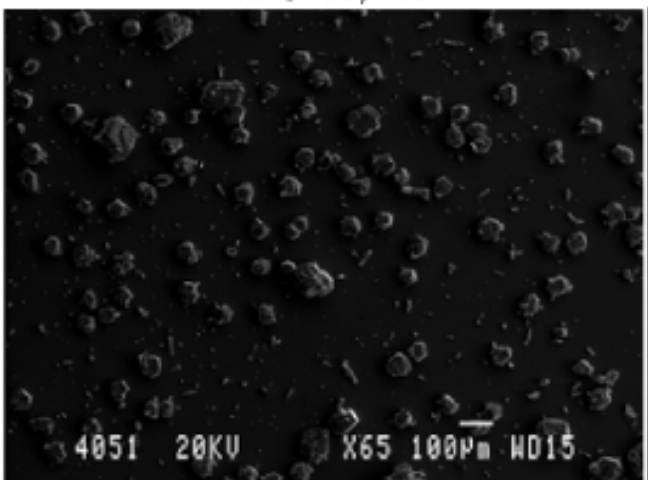

C: Smp, seed, $15^{\circ} \mathrm{C}, \mathrm{x} 65$

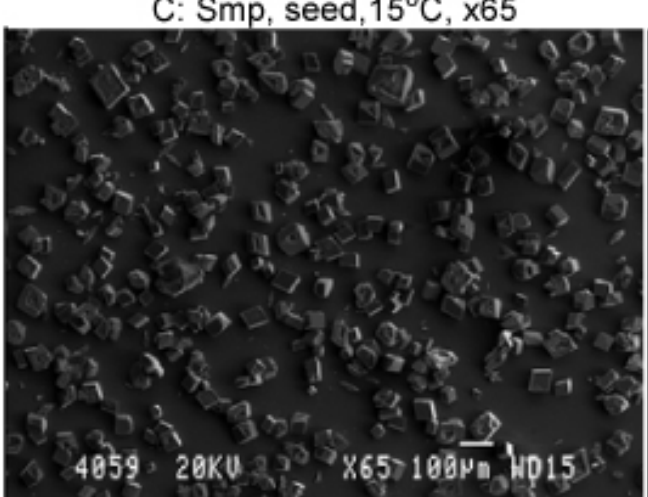

$\mathrm{E}:$ Smp, seed, $35^{\circ} \mathrm{C}, \mathrm{x} 65$

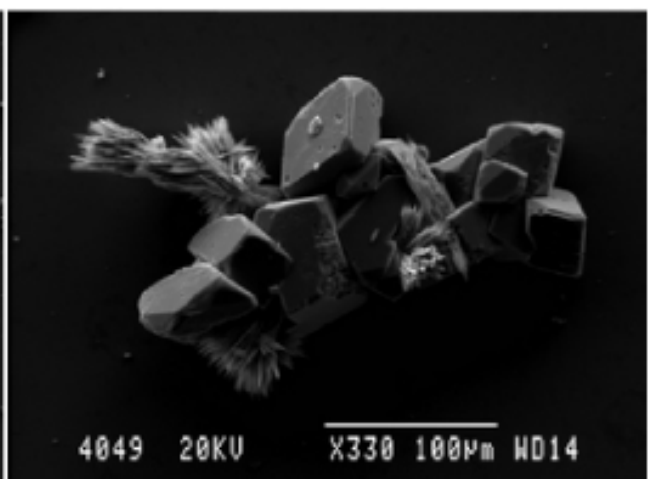

B: Seed, $x 330$

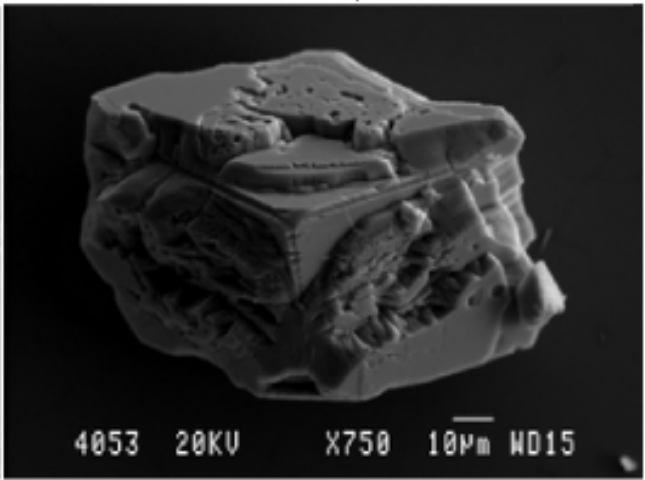

D: Overgrowth on calcite, $x 750$

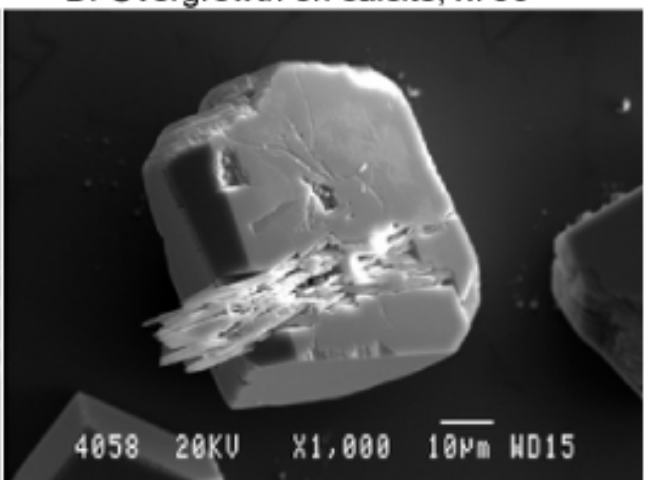

F: Overgrowth on aragonite, $\times 1000$

Figure 4: Example SEM imagery of seed and sample growth on the glass plates. In all cases, the seed carbonate material was grown in a beaker-type setup, whilst the sample material was grown on top of the seed substrate in cave-analogue conditions. The experimental sample growth is dominated by calcite, with no obvious variation in grain morphology with temperature or drip rate. SEM imagery is from a JEOL JSM-840A. A: Seed carbonate growth at $65 x$ magnification $\mathbf{B}$ : Seed growth at 330x magnification. C: Seed and sample growth at $15^{\circ} \mathrm{C}, 1.6$ drips/min. $65 \mathrm{x}$ magnification. D: $15^{\circ} \mathrm{C}, 1.6 \mathrm{drips} / \mathrm{min}$. $750 \mathrm{x}$ magnification. Interpreted as calcite overgrowth of a seed calcite rhomb. E: Seed and sample growth at $35^{\circ} \mathrm{C}, 1.6 \mathrm{drips} / \mathrm{min}$. $65 \mathrm{x}$ magnification. F: $25^{\circ} \mathrm{C}, 1.6$ drips/min. 1000x magnification. Interpreted as calcite overgrowth of seed aragonite. 


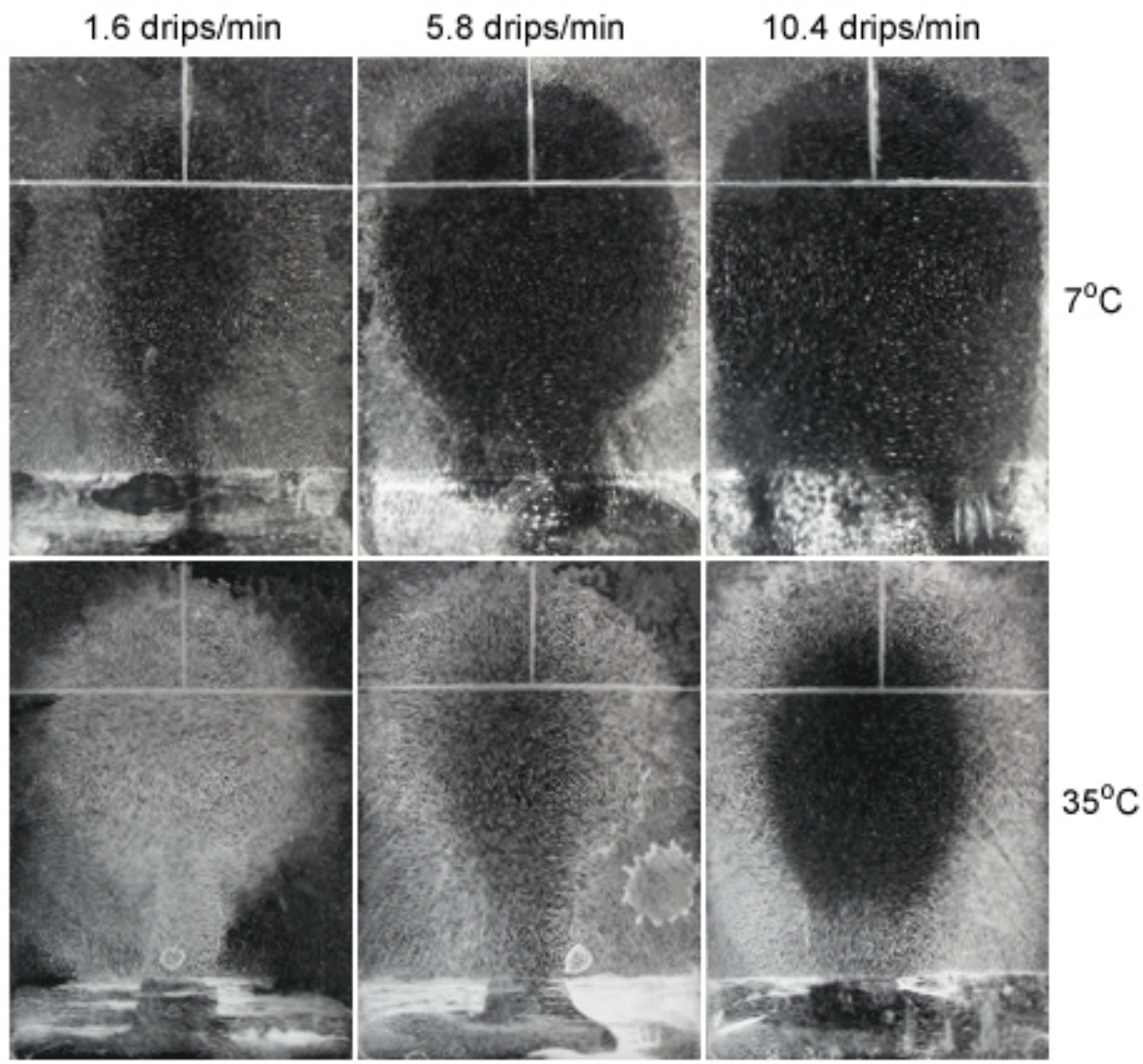

Figure 5: Photographs in crossed-polar light of sample growth at 7 and $35^{\circ} \mathrm{C}$ for all three drip rates. The photographs illustrate the increase in growth mass at higher temperatures and differences in the distribution of calcite-growth with drip rate. With faster drip rate there is increased calcite growth further from the drip location. 
A

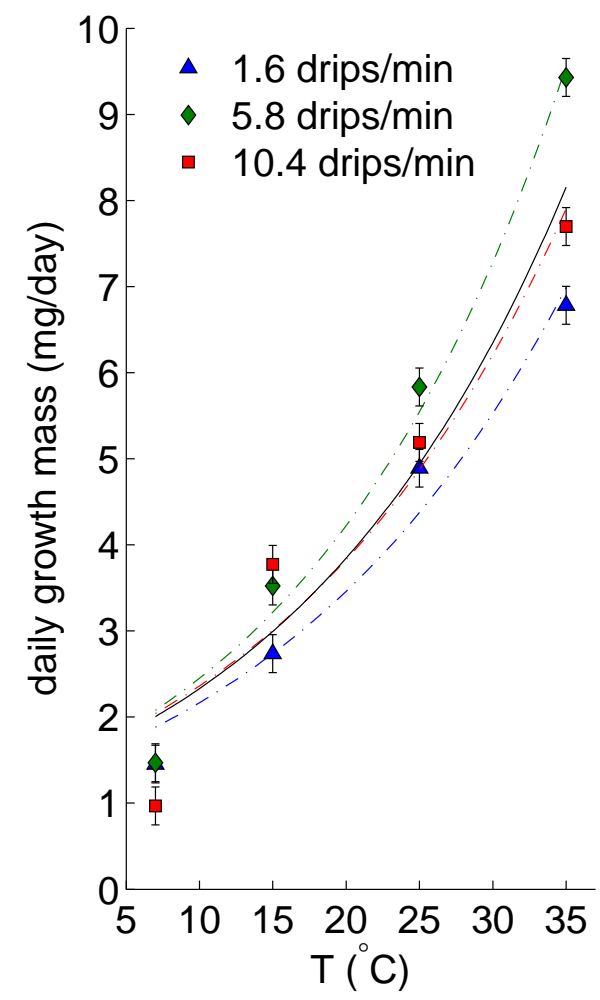

B

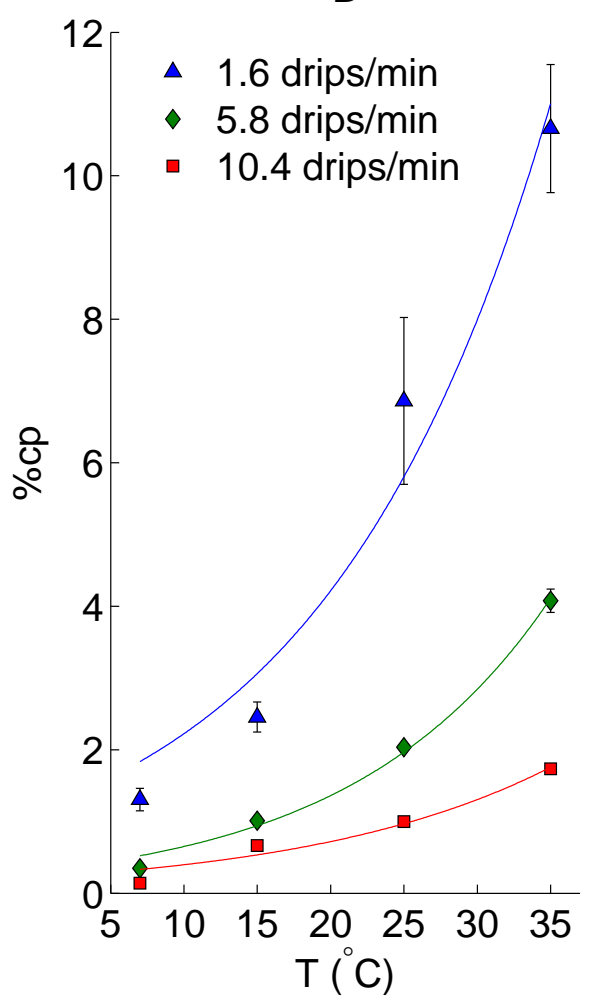

Figure 6: A: Whole-plate daily growth mass (mg/day) versus temperature for all three drip rates. The broken lines are the curves of best fit for each of the drip rates. The continuous black line is the exponential curve of best fit for all drip rates: daily growthmass $=1.4 e^{0.05[ \pm 0.001] T}$. Data is tabulated in table 3. B: Whole plate percent calcite precipitated $(\% \mathrm{cp})$ versus temperature for all three drip rates. The equations for the exponential curves of best fit are: $\% c p=1.2 e^{0.064[ \pm 0.006] T}, \% c p=0.31 e^{0.073[ \pm 0.003] T}$ and $\% c p=0.22 e^{0.060[ \pm 0.002] T}$ for the slow, medium and fast drip rates respectively.. Data is tabulated in table 4. 


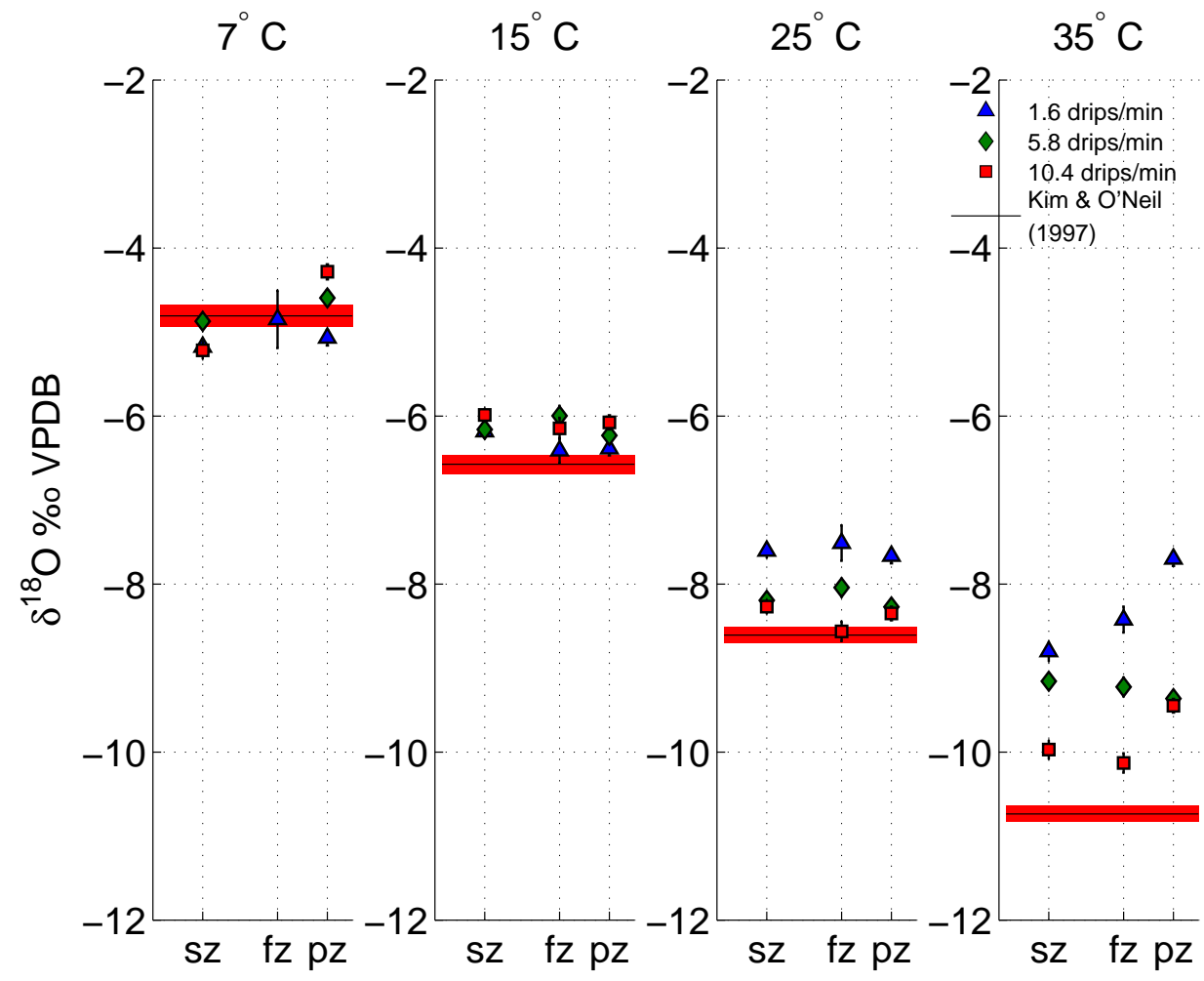

Figure 7: $\delta^{18} O_{\text {calcite }}$ experimental results for all temperatures, drip rates and locations on the glass plate. Error bars include uncertainty on seed correction. Temperature increases from left to right. The abscissa indicates the location of growth on the glass plate, where 'sz' indicates splash zone, 'fz' indicates flow zone and 'pz' indicates ponded zone (c.f. figure 3). The abscissa origin is indicative of the drip impact site and the distance of flow along the plate increases from left to right. Drip rates are distinguished with different symbols: triangles, lozenges and squares for the slow, medium and fast drip rates respectively. The continuous black line at each temperature represents predicted equilibrium values based on the $\alpha_{\text {calcite-water }}$ fractionation factor derived empirically by Kim \& O’Neil (1997). The shaded area around this line is the combined error associated with the Kim \& O'Neil (1997) equation between $\alpha_{\text {calcite-water }}$ and temperature using uncertainty on this study's measurements of $\delta^{18} \mathrm{O}_{\mathrm{H}_{2}} \mathrm{O}$. 


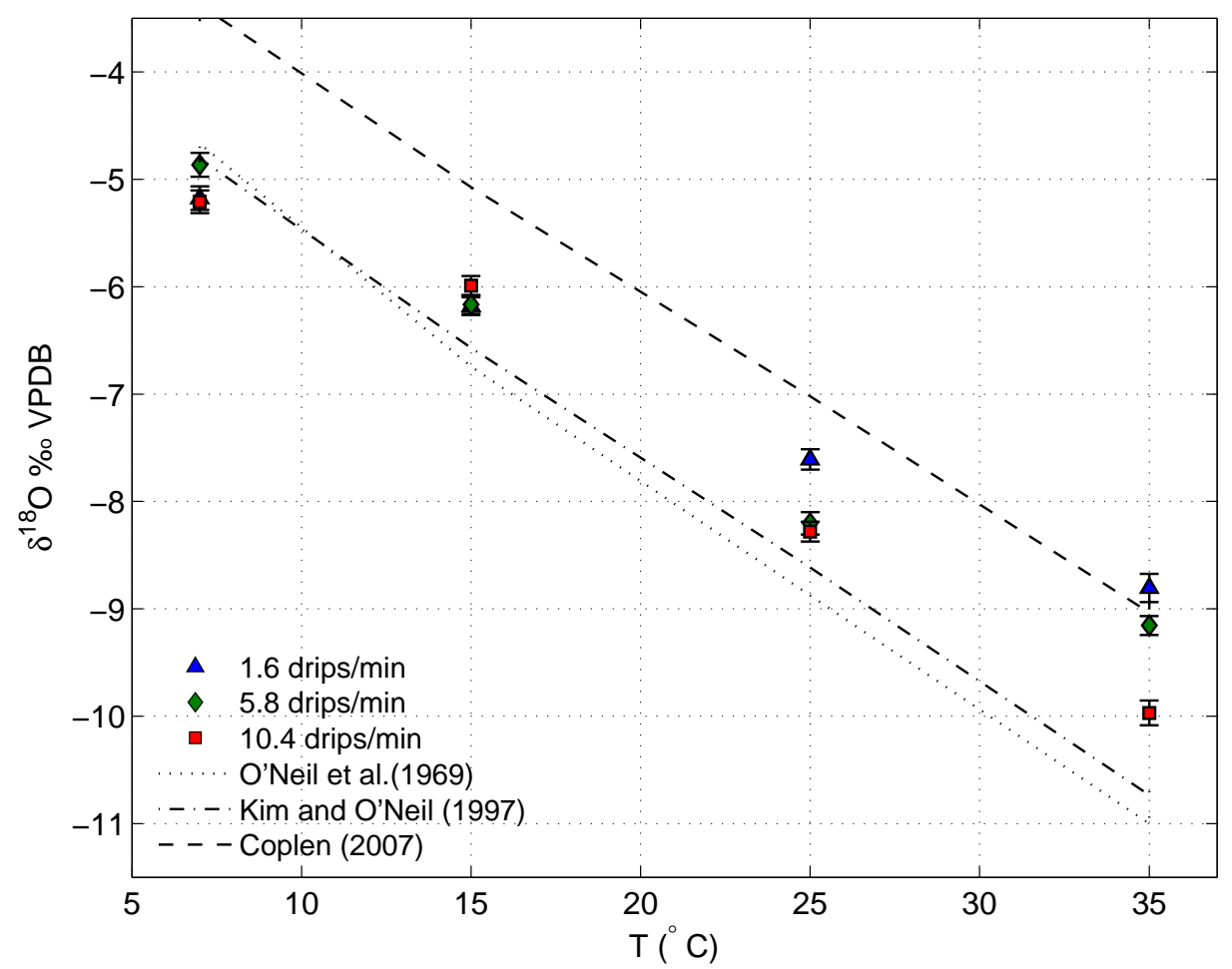

Figure 8: Comparison of splash zone $\delta^{18} O_{\text {calcite }}$ values from this study with the predicted equilibrium values from O'Neil et al. (1969), Kim \& O'Neil (1997) and Coplen (2007). Triangles, lozenges and squares represent the slow, medium and fast drip rate $\delta^{18} O_{\text {calcite }}$ values from the present study. The dash-dot line represents the predicted equilibrium $\delta^{18} O_{\text {calcite }}$ based on O'Neil et al. (1969) equilibrium $\alpha_{\text {calcite-water }}$ values and measurement of solution $\delta^{18} \mathrm{O}_{\mathrm{H}_{2} \mathrm{O}}$. The continuous line and the dashed line represent predicted equilibrium $\delta^{18} O_{\text {calcite }}$ from Kim \& O’Neil (1997) and Coplen (2007) respectively. 


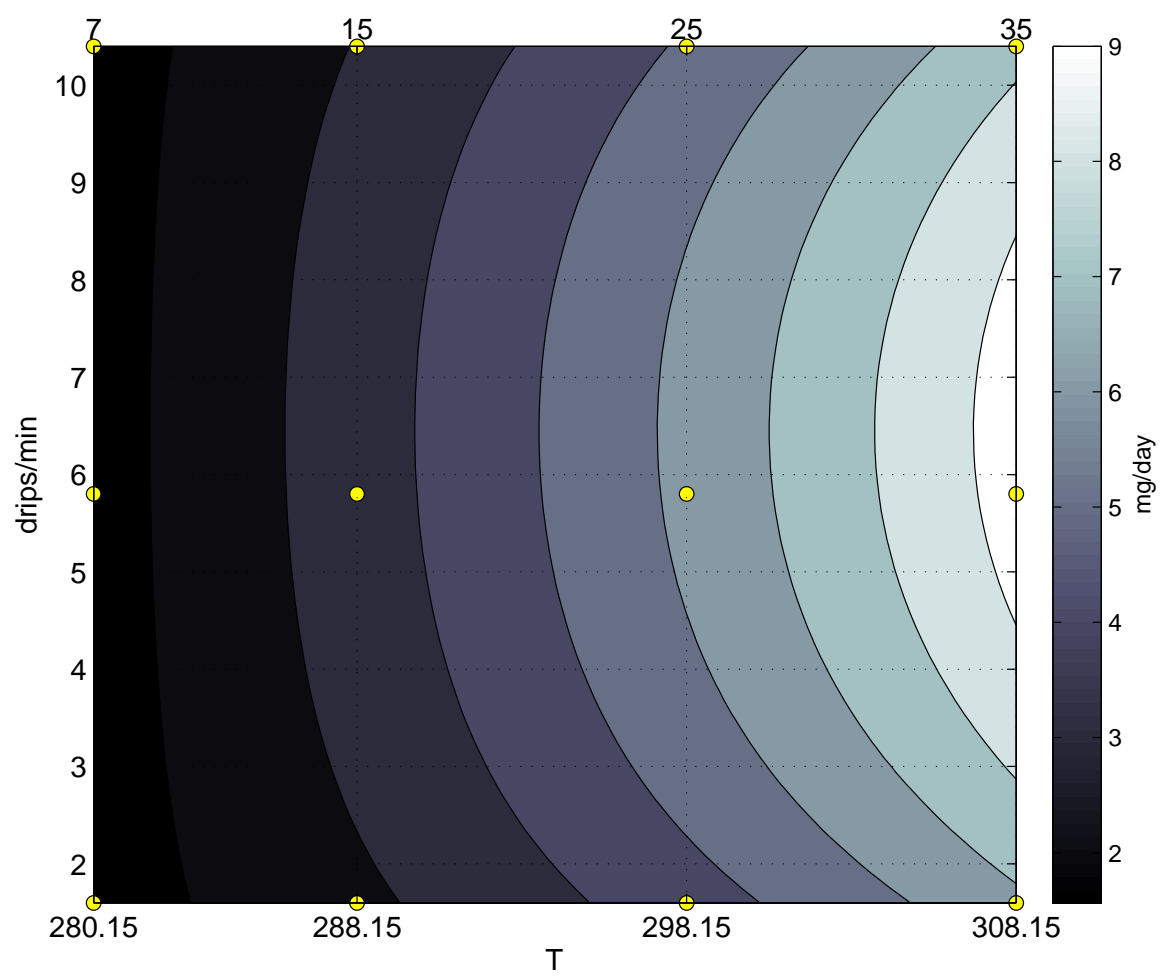

Figure 9: Whole-plate growth mass (mg/day) as a function of drip rate (drips/min) and temperature (kelvin). Daily growth mass values (mg/day) are represented as contours, based on the function of best fit: dailygrowthmass $=1.254+1.478 * 10^{-9} * e^{0.0679 T}+\left(e^{0.00248 T}-2\right) *\left(-0.779 d \_r^{2}+10.05 d \_r+11.69\right)$, where d_r is drip rate in drips/min and T is temperature in kelvin. $R^{2}=0.99$, adjusted- $R^{2}=0.98$ (adjusted $R^{2}$ to account for the decreased degrees of freedom induced by function coefficients) and Root Mean Square Error $R M S E=0.38(\mathrm{mg} /$ day $)$ attest to the robust fit of this function to the empirical data. The round dots represent the empirical values from which this function was derived. 


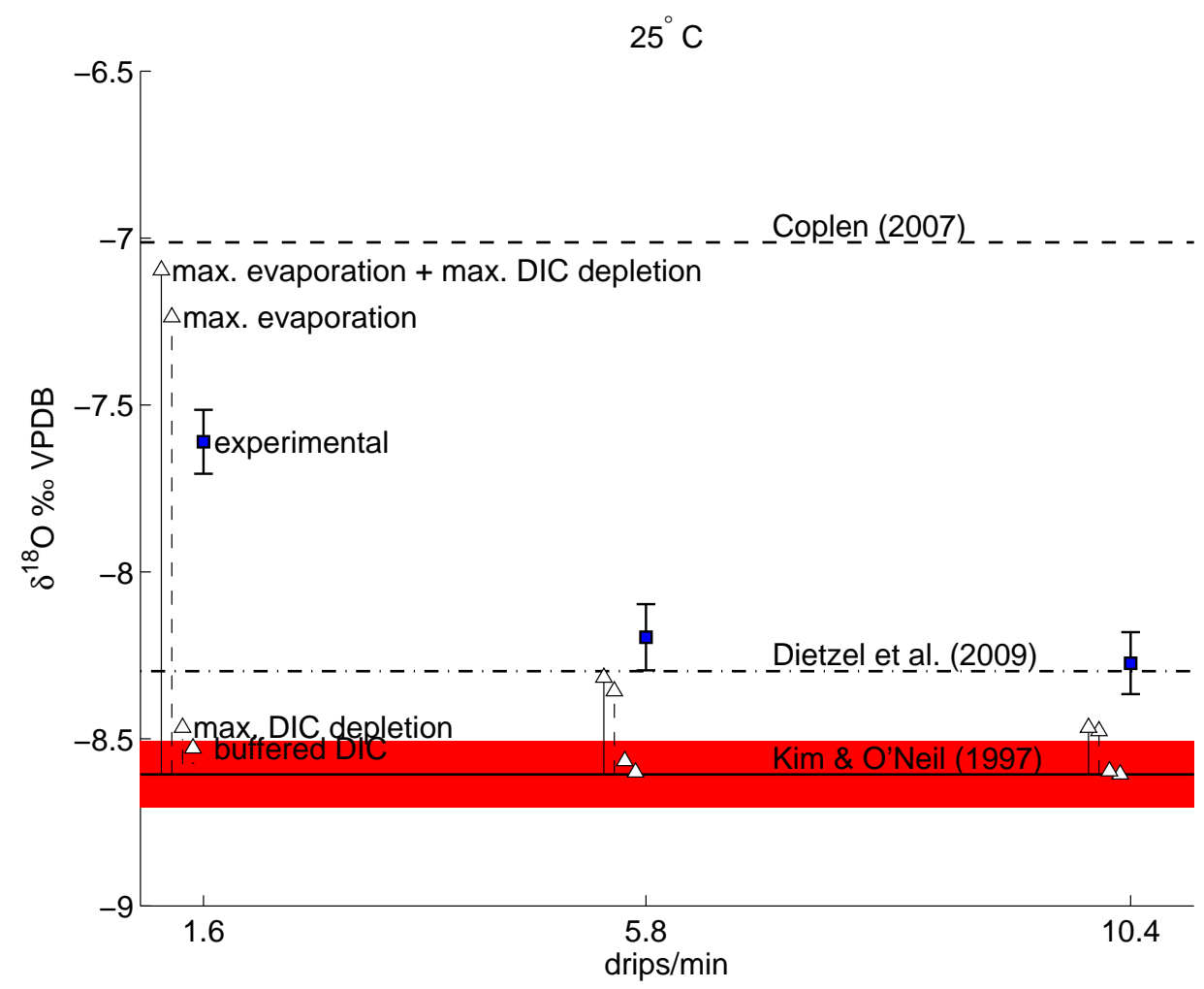

Figure 10: Measured $\delta^{18} O_{\text {calcite }}$ versus drip rate at $25^{\circ} \mathrm{C}$ compared to predicted equilibrium values and estimates of the amount of kinetic fractionation induced by evaporation and rapid DIC-depletion. Filled squares are the experimental results from the $25^{\circ} \mathrm{C}$ experiments. The continuous black line (and associated shaded area) denotes the predicted equilibrium $\delta^{18} O_{\text {calcite }}$ (and associated uncertainty) from Kim \& O'Neil (1997). The dashed horizontal line denotes the predicted equilibrium $\delta^{18} O_{\text {calcite }}$ from Coplen (2007). The dash-dot horizontal line denotes the 'apparent-equilibrium' $\delta^{18} O_{\text {calcite }}$ based on the relationship between precipitation rate (R) and $\alpha_{\text {calcite-water }}$ (Dietzel et al. 2009), for $R=113 \mu \mathrm{mol} \mathrm{m}^{-2} \mathrm{~h}^{-1}$. Vertical, unbroken arrows represent the range of $\delta^{18} O_{\text {calcite }}$ induced by both evaporation and rapid DIC-depletion. 


\begin{tabular}{|c|c|c|c|c|}
\hline Temperature $\left({ }^{\circ} \mathrm{C}\right)$ & 7 & 15 & 25 & 35 \\
\hline $\mathrm{pH}$ & $6.9 \pm 0.2$ & $6.9 \pm 0.1$ & $6.8 \pm 0.2$ & $6.9 \pm 0.1$ \\
\hline$\delta^{18} \mathrm{O}_{\mathrm{H}_{2} \mathrm{O}}$ & $-6.20 \pm 0.07$ & $-6.35 \pm 0.07$ & $-6.36 \pm 0.07$ & $-6.46 \pm 0.07$ \\
\hline air flow rate & 3.5 & 3.5 & 5 & 7 \\
\hline$\rho$ & $3.9 * 10^{-4}$ & $1.3 * 10^{-2}$ & $2.3 * 10^{-2}$ & $4.0 * 10^{-2}$ \\
\hline$[\mathrm{Li}]$ & $1.4 * 10^{-3}$ & $1.2 * 10^{-3}$ & $1.0 * 10^{-3}$ & $8.7 * 10^{-4}$ \\
\hline$[\mathrm{Na}]$ & $4.3 * 10^{-2}$ & $3.7 * 10^{-2}$ & $3.1 * 10^{-2}$ & $2.6 * 10^{-2}$ \\
\hline$[\mathrm{Mg}]$ & $3.1 * 10^{-1}$ & $2.6 * 10^{-1}$ & $2.2 * 10^{-1}$ & $1.9 * 10^{-1}$ \\
\hline$[\mathrm{Ca}]$ & 4.0 & 3.4 & 2.9 & 2.4 \\
\hline$[\mathrm{Co}]$ & & & $1.2 * 10^{-4}$ & $1.0 * 10^{-4}$ \\
\hline$[\mathrm{Sr}]$ & $4.8 * 10^{-3}$ & $4.0 * 10^{-3}$ & $3.4 * 10^{-3}$ & $2.9 * 10^{-3}$ \\
\hline$[\mathrm{Cd}]$ & $8.9 * 10^{-5}$ & $7.5 * 10^{-5}$ & $6.3 * 10^{-5}$ & $5.4 * 10^{-5}$ \\
\hline$[\mathrm{Ba}]$ & & & $1.3 * 10^{-2}$ & $1.1 * 10^{-2}$ \\
\hline$[\mathrm{U}]$ & $6.5 * 10^{-5}$ & $5.5 * 10^{-5}$ & $4.6 * 10^{-5}$ & $3.9 * 10^{-5}$ \\
\hline
\end{tabular}

Table 1: Experimental growth conditions. At each temperature, experiments were conducted at three drip rates: $1.6 \pm 0.1,5.8 \pm 0.2$ and $10.4 \pm 0.5 \mathrm{drips} / \mathrm{min}(2 \mathrm{~s}, \mathrm{n}=30)$. For all experiments, $\log p C \mathrm{O}_{2}$ of the dissolution chamber is maintained at -1.70 and $\log \mathrm{pCO}_{2}$ of the precipitation chamber is maintained at less than -2.60 . The calcite saturation index $\left(S I_{\text {calcite }}\right)$ of the initial solution in the dissolution chamber is maintained constant at 0.34 (equivalent to $\Omega=2.2$ ) for all temperatures. $S I_{\text {aragonite }}=0.21$. All solution measurements relate to the starting solution, before degassing occurs in the precipitation flask. $\delta^{18} \mathrm{O}_{\mathrm{H}_{2} \mathrm{O}}$ is expressed in $\%$, quoted relative to V-SMOW. The 'air flow rate' is the flow rate $\left(L * \mathrm{~min}^{-1}\right)$ of pre-humidified and temperature adusted laboratory air for flushing out degassed $\mathrm{CO}_{2}$ from the precipitation chamber. $\rho$ is the mass of water in air for a given temperature $\left(g * L^{-1}\right)$ HyperPhysics(webpage) (2009). All trace element concentrations are expressed in $\mathrm{mmol} / \mathrm{L}$. All errors are \pm 2 s.d. 


\begin{tabular}{|c|c|c|c|}
\hline Drip rate & $1.6 \pm 0.1$ & $5.8 \pm 0.2$ & $10.4 \pm 0.5$ \\
\hline DIC & 11 & 42 & 76 \\
\hline Precipiated $\mathrm{CaCO}_{3}$ & $2.42 * 10^{-1}$ & $2.44 * 10^{-1}$ & $1.82 * 10^{-1}$ \\
\hline Solution flow rate & $1.3 * 10^{-1}$ & $6.7 * 10^{-1}$ & $12.9 * 10^{-1}$ \\
\hline
\end{tabular}

Table 2: Parameters used to calculate the maximum effect of rapid DIC-depletion and evaporation on $\delta^{18} O_{\text {stalagmite }}$ for the slow, medium and fast drip rate experiments at $25^{\circ} \mathrm{C}$ (c.f. section 4.3). Drip rate in drips/min. DIC is the amount of DIC (mmol) that flows over each of the glass plates during the course of the experiment (7 days). Precipitated $\mathrm{CaCO}_{3}$ is the amount of $\mathrm{CaCO}_{3}(\mathrm{mmol})$ precipitated within the archive, SEM and splash zone areas of the glass plate (c.f. figure 3). Solution flow rate is the flow rate $\left(g * \mathrm{~min}^{-1}\right)$ of drip solution over the glass plates. 


\begin{tabular}{|c|c|c|c|}
\hline \multicolumn{5}{|c|}{ Whole Plate growth mass } \\
\hline $\mathbf{T}$ & $\mathbf{1 . 6}$ drips/min & $\mathbf{5 . 8}$ drips/min & 10.4 drips/min \\
\hline 7 & $1.45+/-0.22$ & $1.47+/-0.22$ & $0.97+/-0.22$ \\
\hline 15 & $2.74+/-0.22$ & $3.52+/-0.22$ & $3.77+/-0.22$ \\
\hline 25 & $4.89+/-0.22$ & $5.83+/-0.22$ & $5.19+/-0.22$ \\
\hline 35 & $6.78+/-0.22$ & $9.43+/-0.22$ & $7.70+/-0.22$ \\
\hline \multicolumn{4}{|c|}{ Splash Zone growth mass } \\
\hline T & 1.6 drips/min & 5.8 drips/min & 10.4 drips/min \\
\hline 7 & $0.57+/-0.22$ & $0.33+/-0.19$ & $0.38+/-0.20$ \\
\hline 15 & $1.49+/-0.27$ & $0.91+/-0.22$ & $0.58+/-0.20$ \\
\hline 25 & $2.09+/-0.27$ & $1.62+/-0.26$ & $1.39+/-0.24$ \\
\hline 35 & $3.00+/-0.53$ & $2.69+/-0.27$ & $1.88+/-0.29$ \\
\hline \multicolumn{5}{|c|}{ Flow Zone growth mass } \\
\hline T & 1.6 drips/min & 5.8 drips/min & 10.4 drips/min \\
\hline 7 & $0.25+/-0.23$ & $0.17+/-0.31$ & $0.07+/-0.26$ \\
\hline 15 & $0.64+/-0.36$ & $0.64+/-0.29$ & $0.48+/-0.23$ \\
\hline 25 & $0.45+/-0.31$ & $1.37+/-0.29$ & $1.05+/-0.22$ \\
\hline 35 & $1.33+/-0.36$ & $1.71+/-0.26$ & $2.18+/-0.32$ \\
\hline \multicolumn{5}{|c|}{ Ponded Zone growth mass } \\
\hline T & 1.6 drips/min & 5.8 drips/min & 10.4 drips/min \\
\hline 7 & $0.42+/-0.21$ & $0.67+/-0.19$ & $0.38+/-0.20$ \\
\hline 15 & $0.60+/-0.23$ & $1.40+/-0.22$ & $1.71+/-0.21$ \\
\hline 25 & $0.65+/-0.21$ & $1.10+/-0.21$ & $1.35+/-0.21$ \\
\hline 35 & $1.12+/-0.21$ & $2.84+/-0.25$ & $1.89+/-0.22$ \\
\hline
\end{tabular}

Table 3: Sample growth mass (mg/day) for the whole plate and subsequently broken down between the splash, flow and ponded zones. The difference between the sum of the splash, flow \& ponded zone sample masses and the whole plate growth mass is accounted for by the mass of sample growth within the archive and SEM zones (c.f. figure 3). 


\begin{tabular}{|c|c|c|c|}
\hline \multicolumn{5}{|c|}{ Whole Plate \%cp } \\
\hline T & 1.6 drips/min & 5.8 drips/min & 10.4 drips/min \\
\hline 7 & $1.41+/-0.19 \%$ & $0.38+/-0.02 \%$ & $0.13+/-0.02 \%$ \\
\hline 15 & $2.87+/-0.28 \%$ & $1.01+/-0.06 \%$ & $0.56+/-0.02 \%$ \\
\hline 25 & $6.44+/-0.96 \%$ & $2.09+/-0.04 \%$ & $0.97+/-0.05 \%$ \\
\hline 35 & $10.64+/-0.86 \%$ & $4.08+/-0.17 \%$ & $1.73+/-0.04 \%$ \\
\hline \multicolumn{4}{|c|}{ Splash Zone \%cp } \\
\hline T & 1.6 drips/min & 5.8 drips/min & 10.4 drips/min \\
\hline 7 & $0.51+/-0.07 \%$ & $0.08+/-0.01 \%$ & $0.06+/-0.01 \%$ \\
\hline 15 & $1.32+/-0.13 \%$ & $0.26+/-0.02 \%$ & $0.10+/-0.01 \%$ \\
\hline 25 & $2.99+/-0.45 \%$ & $0.56+/-0.02 \%$ & $0.27+/-0.02 \%$ \\
\hline 35 & $4.71+/-0.42 \%$ & $1.16+/-0.05 \%$ & $0.42+/-0.01 \%$ \\
\hline \multicolumn{5}{|c|}{ Flow Zone \% cp (cumulative) } \\
\hline T & 1.6 drips/min & 5.8 drips/min & 10.4 drips/min \\
\hline 7 & $0.73+/-0.11 \%$ & $0.12+/-0.02 \%$ & $0.07+/-0.01 \%$ \\
\hline 15 & $1.89+/-0.20 \%$ & $0.44+/-0.03 \%$ & $0.19+/-0.01 \%$ \\
\hline 25 & $3.64+/-0.55 \%$ & $1.04+/-0.03 \%$ & $0.47+/-0.03 \%$ \\
\hline 35 & $6.79+/-0.60 \%$ & $1.90+/-0.09 \%$ & $0.91+/-0.03 \%$ \\
\hline \multicolumn{5}{|c|}{ Ponded Zone \%cp (cumulative) } \\
\hline T & 1.6 drips/min & 5.8 drips/min & 10.4 drips/min \\
\hline 7 & $1.10+/-0.16 \%$ & $0.28+/-0.03 \%$ & $0.12+/-0.02 \%$ \\
\hline 15 & $2.43+/-0.25 \%$ & $0.84+/-0.06 \%$ & $0.49+/-0.03 \%$ \\
\hline 25 & $4.56+/-0.71 \%$ & $1.42+/-0.05 \%$ & $0.73+/-0.05 \%$ \\
\hline 35 & $8.55+/-0.76 \%$ & $3.13+/-0.14 \%$ & $1.34+/-0.04 \%$ \\
\hline \multicolumn{4}{|c|}{}
\end{tabular}

Table 4: Percent calcite precipitated (\%cp) values. The flow and ponded zone $\% \mathrm{cp}$ values are cumulative, i.e. they incorporate the mass of calcite precipitated upstream of that point on the plate (c.f. figure 3). The reason for 'ponded zone \%cp' < 'whole plate \%cp' is that sample growth within the archive and SEM zones (c.f. figure 3 ) is unaccounted for in this table. 


\begin{tabular}{|c|c|c|c|}
\hline \multicolumn{4}{|c|}{ Splash Zone $\delta^{18} O_{\text {calcite }}$} \\
\hline $\mathbf{T}$ & 1.6 drips/min & $5.8 \mathrm{drips} / \mathrm{min}$ & $10.4 \mathrm{drips} / \mathrm{min}$ \\
\hline 7 & $-5.18+/-0.11 \% 0$ & $-4.87+/-0.11 \% 0$ & $-5.21+/-0.12 \% 0$ \\
\hline 15 & $-6.19+/-0.09 \%$ & $-6.16+/-0.09 \% 0$ & $-5.99+/-0.08 \% 0$ \\
\hline 25 & $-7.60+/-0.09 \%$ & $-8.20+/-0.10 \%$ & $-8.27+/-0.10 \%$ \\
\hline 35 & $-8.80+/-0.14 \% 0$ & $-9.16+/-0.09 \% 0$ & $-9.97+/-0.12 \% 0$ \\
\hline \multicolumn{4}{|c|}{ Flow Zone $\delta^{18} O_{\text {calcite }}$} \\
\hline $\mathbf{T}$ & 1.6 drips/min & $5.8 \mathrm{drips} / \mathrm{min}$ & 10.4 drips/min \\
\hline 7 & $-4.86+/-0.23 \%$ & $-3.37+/-1.49 \% 0$ & $-3.09+/-30.09 \% 0$ \\
\hline 15 & $-6.42+/-0.15 \%$ & $-6.00+/-0.12 \% 0$ & $-6.14+/-0.12 \% 0$ \\
\hline 25 & $-7.53+/-0.25 \%$ & $-8.04+/-0.11 \% 0$ & $-8.57+/-0.11 \% 0$ \\
\hline 35 & $-8.43+/-0.15 \%$ & $-9.23+/-0.11 \% 0$ & $-10.13+/-0.11 \% 0$ \\
\hline \multicolumn{4}{|c|}{ Ponded Zone $\delta^{18} O_{\text {calcite }}$} \\
\hline $\bar{T}$ & 1.6 drips/min & $5.8 \mathrm{drips} / \mathrm{min}$ & 10.4 drips/min \\
\hline 7 & $-5.07+/-0.09 \%$ & $-4.60+/-0.09 \% 0$ & $-4.28+/-0.09 \% 0$ \\
\hline 15 & $-6.38+/-0.08 \% 0$ & $-6.23+/-0.09 \% 0$ & $-6.07+/-0.08 \% 0$ \\
\hline 25 & $-7.67+/-0.09 \%$ & $-8.27+/-0.08 \% 0$ & $-8.35+/-0.08 \% 0$ \\
\hline 35 & $-7.70+/-0.08 \% 0$ & $-9.36+/-0.08 \% 0$ & $-9.45+/-0.08 \% 0$ \\
\hline
\end{tabular}

Table 5: $\delta^{18} O_{\text {calcite }}$ results for the splash, flow and ponded zones (c.f. figure 3). $\delta^{18} O_{\text {calcite }}$ error, beyond the analytical error $(0.08 \% 0)$, is caused by seed correction. 


\section{References}

AyAlon, A, BAR-MATthews, M, \& SASs, E. 1998. Rainfall-recharge relationships within a karstic terrain in the eastern Mediterranean semi-arid region, Israel: delta O-18 and delta D characteristics. Journal of Hydrology, 207(1-2), 18-31. 3

Baker, A, Genty, D, Dreybrodt, W, Barnes, Wl, Mockler, NJ, \& Grapes, J. 1998. Testing theoretically predicted stalagmite growth rate with Recent annually laminated samples: Implications for past stalagmite deposition. Geochimica Et Cosmochimica Acta, 62(13), 2405-2405. 5

BAKER, A, GENTy, D, \& FAIRChILD, IJ. 2000. Hydrological characterisation of stalagmite dripwaters at Grotte de Villars, Dordogne, by the analysis of inorganic species and luminescent organic matter. Hydrology and Earth System Sciences, 4(3), 439-449. 6

Baldini, JUl, McDermott, F, Baker, A, Baldini, LM, Mattey, DP, \& Railsback, LB. 2005. Biomass effects on stalagmite growth and isotope ratios: A 20th century analogue from Wiltshire, England. Earth and Planetary Science Letters, 240(2), 486-494. 18

Bar-Matthews, M, Ayalon, A, Gilmour, M, Matthews, A, \& Hawkesworth, CJ. 2003. Sea-land oxygen isotopic relationships from planktonic foraminifera and speleothems in the Eastern Mediterranean region and their implication for paleorainfall during interglacial intervals. Geochimica Et Cosmochimica Acta, 67(17), 3181-3199. 3

Beck, WC, Grossman, EL, \& MORSE, JW. 2005. Experimental studies of oxygen isotope fractionation in the carbonic acid system at 15 degrees, 25 degrees, and 40 degrees C. Geochimica Et Cosmochimica Acta, 69(14), 3493-3503. 15, 16

BrenninkmeIJER, CAM, KrAft, P, \& Mook, WG. 1983. Oxygen isotope fractionation between CO2 and H2O. Isotope Geoscience, 1(2), 181-190. 15

COPLEN, T.B. 1996. New guidelines for reporting stable hydrogen, carbon, and oxygen isotope-ratio data. Geochimica et Cosmochimica Acta, 60(17), 3359-3360. 11

Coplen, T.B. 2007. Calibration of the calcite-water oxygen-isotope geothermometer at Devils Hole, Nevada, a natural laboratory. Geochimica Et Cosmochimica Acta, 71(16), 3948-3957. 2, 4, 17, 18, 21, 29, 31

DANSGAARD, W. 1964. Stable isotopes in precipitation. Tellus, 16(4), 436-468. 3 
Dietzel, M., TAng, J., Leis, A., \& Koehler, S.J. 2009. Oxygen isotopic fractionation during inorganic calcite precipitation - Effects of temperature, precipitation rate and pH. Chemical Geology, 268(1-2), 107115. $2,4,15,16,17,18,20,21,31$

Dorale, J.A., \& LIU, Z.B. 2009. Limitations of hendy test criteria in judging the paleoclimatic suitability of speleothems and the need for replication. Journal of Cave and Karst Studies, 71(1), 73-80. cited By (since 1996) 1.3

Dorale, JA, Edwards, RL, Ito, E, \& Gonzalez, LA. 1998. Climate and vegetation history of the midcontinent from 75 to $25 \mathrm{ka}$ : A speleothem record from Crevice Cave, Missouri, USA. Science, 282(5395), 1871-1874. 3

DREYBRODT, W. 2008. Evolution of the isotopic composition of carbon in a calcite precipitating $\mathrm{H}_{2} \mathrm{O}_{-} \mathrm{CO}_{2}-$ $\mathrm{CaCO}_{3}$ solution and the related isotopic composition of calcite in stalagmites. Geochimica Et Cosmochimica Acta, 72(19), 4712-4724. 18

Dykoski, CA, Edwards, RL, Cheng, H, Yuan, DX, CAi, YJ, Zhang, ML, Lin, YS, QIng, JM, An, ZS, \& Revenaugh, J. 2005. A high-resolution, absolute-dated Holocene and deglacial Asian monsoon record from Dongge Cave, China. Earth and Planetary Science Letters, 233(1-2), 71-86. 3

FANTIDIS, J., \& EHHALT, D.H. 1970. Variations of the carbon and oxygen isotopic composition in stalagmites and stalactites: Evidence of non-equilibrium isotopic fractionation. Earth and Planetary Science Letters, 10(1), 136-144. 4

Faure, G., \& Mensing, T.M. 2005. Isotopes principles and applications. Wiley. Chap. Fractionation of Stable Isotopes. 16

Fleitmann, D, Burns, SJ, Mudelsee, M, Neff, U, Kramers, J, Mangini, A, \& Matter, A. 2003.

Holocene forcing of the Indian monsoon recorded in a stalagmite from Southern Oman. Science, 300(5626), 1737-1739. 3

Genty, D. 2008. Palaeoclimate Research in Villars Cave (Dordogne, SW-France). International Journal of Speleology, 37(3), 173-191. 4, 18

Genty, D, \& Deflandre, G. 1998. Drip flow variations under a stalactite of the Père Nöel cave (Belgium). Evidence of seasonal variations and air pressure constraints. Journal of Hydrology, 211(1-4), 208-232. 7 
Genty, D, Blamart, D, Ouahdi, R, Gilmour, M, Baker, A, Jouzel, J, \& Van-Exter, S. 2003. Precise dating of Dansgaard-Oeschger climate oscillations in western Europe from stalagmite data. Nature, 421(6925), 833-837. 3

Hall, Gem, Pelchat, JC, Pelchat, P, \& Vaive, JE. 2002. Sample collection, filtration and preservation protocols for the determination of 'total dissolved' mercury in waters. Analyst, 127(5), 674-680. 5

Henderson, GM. 2006. Caving in to new chronologies. Science, 313(5787), 620-622. 3

HENDY, CH. 1971. Isotopic geochemistry of speleothems-I. calculations of effects of difference modes of formation on isotopic composition of speleothems and their applicability as palaeoclimatic indicators. Geochimica Et Cosmochimica Acta, 35(8), 801-\&. 3, 14, 15, 16, 19

Horita, J., \& Clayton, R.N. 2007. Comment on the studies of oxygen isotope fractionation between calcium carbonates and water at low temperatures by Zhou and Zheng $(2003 ; 2005)>$. Geochimica et Cosmochimica Acta, 71(12), 3131-3135. cited By (since 1996) 6. 10

HuAng, YM, \& FAIRChIld, IJ. 2001. Partitioning of $S r^{2+}$ and $M g^{2+}$ into calcite under karst-analogue experimental conditions. Geochimica Et Cosmochimica Acta, 65(1), 47-62. 4

HyPerPhysiCs(WEBPAGE). 2009. Saturated Vapor Pressure, Density for Water. http://hyperphysics.phyastr.gsu.edu/HBASE/kinetic/watvap.html, August. 16, 32

Johnson, KR, Hu, CY, Belshaw, NS, \& Henderson, GM. 2006. Seasonal trace-element and stableisotope variations in a Chinese speleothem: The potential for high-resolution paleomonsoon reconstruction. Earth and Planetary Science Letters, 244(1-2), 394-407. 18

Kim, Sang-Tae, Hillaire-Marcel, Claude, \& Mucci, Alfonso. 2006. Mechanisms of equilibrium and kinetic oxygen isotope effects in synthetic aragonite at 25 degrees C. Pages A318-A318 of: Geochimica Et Cosmochimica Acta, vol. 70. THE BOULEVARD, LANGFORD LANE, KIDLINGTON, OXFORD OX5 1GB, ENGLAND: PERGAMON-ELSEVIER SCIENCE LTD. 19

KIM, S.T., \& O’NEIL, J.R. 1997. Equilibrium and nonequilibrium oxygen isotope effects in synthetic carbonates. Geochimica Et Cosmochimica Acta, 61(16), 3461-3475. 2, 4, 8, 10, 11, 16, 17, 18, 19, 21, 28, 29, 31

LACHNIET, M.S. 2009. Climatic and environmental controls on speleothem oxygen-isotope values. Quaternary Science Reviews, 28(5-6), 412-432. cited By (since 1996) 12. 3 
LAKSHTANOV, LZ, \& STIPP, SLS. 2004. Experimental study of Europium(III) coprecipitation with calcite. Geochimica Et Cosmochimica Acta, 68(4), 819-827. 9

LAXEN, DPH, \& HARRISON, RM. 1981. Cleaning methods for polythene containers prior to the determination of trace-metals in fresh-water samples. Analytical Chemistry, 53(2), 345-350. 5

LEGRAnde, AN, \& SCHMidT, GA. 2006. Global gridded data set of the oxygen isotopic composition in seawater. Geophysical Research Letters, 33(12). 3

Lin, Y.-P., Singer P.C. 2005. Effects of seed material and solution composition on calcite precipitation. Geochimica et Cosmochimica Acta, 69(18), 4495-4504. cited By (since 1996) 11. 9

Mangini, A, Spotl, C, \& Verdes, P. 2005. Reconstruction of temperature in the Central Alps during the past 2000 yr from a delta O-18 stalagmite record. Earth and Planetary Science Letters, 235(3-4), 741-751. 18

MCCREA, JM. 1950. On the isotopic chemistry of carbonates and a paleotemperature scale. Journal of Chemical Physics, 18(6), 849-857. 11

MCDermotT, F. 2004. Palaeo-climate reconstruction from stable isotope variations in speleothems: a review. Quaternary Science Reviews, 23(7-8), 901-918. 3, 6

Mickler, PJ, Stern, LA, \& BAnNer, JL. 2006. Large kinetic isotope effects in modern speleothems. Geological Society of America Bulletin, 118(1-2), 65-81. 3, 4, 8, 15

Mills, G.A., \& UREY, H.C. 1940. The kinetics of isotopic exchange between carbon dioxide, bicarbonate ion, carbonate ion and water. Journal of the American Chemical Society, 62(5), 1019-1026. cited By (since 1996) 60. 14

NELSON, ST. 2000. A simple, practical methodology for routine VSMOW/SLAP normalization of water samples analyzed by continuous flow methods. Rapid Communications In Mass Spectrometry, 14(12), 1044-1046. 11

O’Neil, JR, Clayton, RN, \& MAYEDA, TK. 1969. Oxygen isotope fractionation in divalent metal carbonates. Journal of Chemical Physics, 51(12), 5547-\&. 10, 29

PARKhURST, D.L., \& APPELO, C.A.J. 1999. User's guide to PHREEQC (version 2): a computer program for speciation, batch-reaction, one-dimensional transport, and inverse geochemical calculations. Vol. 994259. Denver, Colo.: U.S. Department of the Interior, U.S. Geological Survey. 6 
Pinsent, B.R.W., \& Roughton, F.J.W. 1951. The kinetics of combination of carbon dioxide with water and hydroxide ions. Transactions of the Faraday Society, 47, 263-269. cited By (since 1996) 8. 14

Spero, HJ, Bijma, J, LEA, DW, \& Bemis, BE. 1997. Effect of seawater carbonate concentration on foraminiferal carbon and oxygen isotopes. Nature, 390(6659), 497-500. 4

Steefel, C.I., Van Cappellen P. 1990. A new kinetic approach to modeling water-rock interaction: The role of nucleation, precursors, and Ostwald ripening. Geochimica et Cosmochimica Acta, 54(10), 26572677. cited By (since 1996) 171. 9

STUMm, WERnER, \& MORGAn, JAMEs J. 1996. Aquatic chemistry: chemical equilibria and rates in natural waters. 3rd ed edn. New York: Wiley. 9

TARutani, T, Clayton, RN, \& Mayeda, TK. 1969. Effect of polymorphism and magnesium substitution on oxygen isotope fractionation between calcium carbonate and water. Geochimica Et Cosmochimica Acta, 33(8), 987-\&. 10

Terakado, Y, \& MAsuda, A. 1988. The coprecipitation of rare-earth elements with calcite and aragonite. Chemical Geology, 69(1-2), 103-110. 9

Treble, PC, Chappell, J, Gagan, MK, McKeegan, KD, \& Harrison, TM. 2005. In situ measurement of seasonal $\delta^{18} O$ variations and analysis of isotopic trends in a modem speleothem from southwest Australia. Earth and Planetary Science Letters, 233(1-2), 17-32. 3

UsDOWSKI, E, \& HoEFS, J. 1993. Oxygen-isotope exchange between carbonic-acid, bicarbonate, carbonate, and water - a reexamination of the data of McCrea (1950) and an expression for the overall partitioning of oxygen isotopes between the carbonate species and water. Geochimica Et Cosmochimica Acta, 57(15), 3815-3818. 16

Wang, XF, Auler, AS, Edwards, Rl, Cheng, H, Cristalli, PS, Smart, Pl, Richards, DA, \& SHEN, CC. 2004. Wet periods in northeastern Brazil over the past $210 \mathrm{kyr}$ linked to distant climate anomalies. Nature, 432(7018), 740-743. 3

Wang, YJ, Cheng, H, Edwards, RL, An, ZS, Wu, JY, Shen, CC, \& Dorale, JA. 2001. A highresolution absolute-dated Late Pleistocene monsoon record from Hulu Cave, China. Science, 294(5550), 2345-2348. 3 
Wiedner, E., Scholz, D., Mangini, A., Polag, D., Muehlinghaus, C., \& Segl, M. 2008. Investigation of the stable isotope fractionation in speleothems with laboratory experiments. Quaternary International, 187(AUG 15), 15-24. 4, 8, 16

ZEEBE, RE. 1999. An explanation of the effect of seawater carbonate concentration on foraminiferal oxygen isotopes. Geochimica Et Cosmochimica Acta, 63(13-14), 2001-2007. 4, 18

Zhang, P.A, Johnson, K.R.B, Chen, Y.A, Chen, F.A, Lynn, I.B, Zhang, X.C, Zhang, C.A, WAng, S.D, PANG, F.E, \& Long, L.E. 2004. Modern systematics and environmental significance of stable isotopic variations in Wanxiang Cave, Wudu, Gansu, China. Chinese Science Bulletin, 49(15), 1649-1652. cited By (since 1996) 5. 3 